Ocean Dynamics

July 2018, Volume 68 , Issue 7 , Pages $779-800$

http://dx.doi.org/10.1007/s10236-018-1159-3

http://archimer.ifremer.fr/doc/00441/55240/

(c) Springer-Verlag GmbH Germany, part of Springer Nature 2018

\title{
Contrasted turbulence intensities in the Indonesian Throughflow: a challenge for parameterizing energy dissipation rate
}

\author{
Bouruet-Aubertot Pascale ${ }^{1,{ }^{*}}$, Cuypers Yannis ${ }^{1}$, Ferron Bruno ${ }^{4}$, Dausse Denis ${ }^{1}$, Ménage Olivier ${ }^{2}$, \\ Atmadipoera Agus $^{3}$, Jaya Indra ${ }^{3}$
}

${ }^{1}$ Sorbonne Universit'e- UPMC Universit'e Paris 06- LOCEAN, Paris, France

${ }^{2}$ LOPS-Ifremer, Plouzan'e, France

${ }^{3}$ IPB, Bogor, Indonesia

* Corresponding author : Pascale Bouruet-Aubertot, email address : pba@locean-ipsl.upmc.fr

\begin{abstract}
:
Microstructure measurements were performed along two sections through the Halmahera Sea and the Ombai Strait and at a station in the deep Banda Sea. Contrasting dissipation rates $(\epsilon)$ and vertical eddy diffusivities $(\mathrm{K} \mathrm{z})$ were obtained with depth-averaged ranges of $\sim[9 \times 10-10-10-5] \mathrm{W} \mathrm{kg}-1$ and of $\sim[1 \times 10-5-2 \times 10-3] \mathrm{m} 2 \mathrm{~s}-1$, respectively. Similarly, turbulence intensity, $\mathrm{I}=\epsilon /(\mathrm{vN2})$ with $\mathrm{v}$ the kinematic viscosity and $\mathrm{N}$ the buoyancy frequency, was found to vary seven orders of magnitude with values up to 107. These large ranges of variations were correlated with the internal tide energy level, which highlights the contrast between regions close and far from internal tide generations. Finescale parameterizations of $\epsilon$ induced by the breaking of weakly nonlinear internal waves were only relevant in regions located far from any generation area ("far field"), at the deep Banda Sea station. Closer to generation areas, at the "intermediate field" station of the Halmahera Sea, a modified formulation of MacKinnon and Gregg (2005) was validated for moderately turbulent regimes with $100<\mathrm{I}<1000$. Near generation areas marked by strong turbulent regimes such as "near field" stations within strait and passages, $\epsilon$ is most adequately inferred from horizontal velocities provided that part of the inertial subrange is resolved, according to Kolmogorov scaling.
\end{abstract}

Keywords: Turbulence, Internal tides, Vertical mixing, Parameterization, Indonesian seas, Microstructure measurements 


\section{INTRODUCTION}

The Indonesian seas are a key region of the ocean as they provide a passage at low latitude for Pacific waters toward the Indian ocean (e.g., Sprintall et al., 2004, see Figure 1 of this paper). This inflow, called the Indonesian Throughflow, significantly impacts the thermohaline circulation (e.g., Gordon and Fine, 1996). Indeed, it contributes to the poleward heat flux as Pacific waters are injected into the Indian Ocean and exit within the poleward flowing Aghulas current (Gordon, 2005). In the pycnocline, Pacific waters flowing through the Indonesian seas get progressively cooler and fresher (e.g., Gordon, 2005; Atmadipoera et al., 2009). These water mass transformations result from an intense vertical mixing. They have a significant impact not only through the water column but also on the atmosphere as the cooling of surface waters can affect the onset of deep atmospheric convection (e.g., Gordon, 1986; Koch-Larrouy et al., 2008).

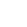

The strong turbulent mixing in the Indonesian Seas was evidenced indirectly by Ffield and Gordon (1996) from the sea surface cooling it induces. Moreover, the temperature signature was found to vary at fortnightly and monthly tidal periods, thus suggesting that vertical mixing is mostly driven by the strong tides present in the area. Other estimates that used the variance of temperature at finescale $(\sim 2-10 \mathrm{~m})$ as a proxy of mixing (Ffield and Robertson, 2005, 2008; Robertson, 2010) showed that the finescale variance is larger in straits and on shelf-slope boundaries where internal tide generation is strong. However, apart from these indirect inferences on the distribution of mixing 
and its possible relationship with internal tides, there has been no direct measurements of the dissipation rate of turbulent kinetic energy at microscale focusing on the role of tides. Microstructure measurements were only performed in the Banda Sea (Alford et al., 1999; Alford and Gregg, 2001). In this region far from any generation area of internal tides, mixing induced by a baroclinic near-inertial wave was evidenced with mean values in the thermocline of the order of $10^{-5} \mathrm{~m}^{2} \mathrm{~s}^{-1}$ for $\mathrm{K}_{z}$ and $10^{-8} \mathrm{~W} \mathrm{~kg}^{-1}$ for $\epsilon$ (Alford et al., 1999; Alford and Gregg, 2001).

Previous observations aimed at characterizing volume and heat transports across the numerous straits of the Indonesian seas (JADE, WOCE and INSTANT; e.g., Sprintall et al., 2004; Schiller et al., 2010; Gordon et al., 2010). The main information on tides relies on numerical models (e.g., Robertson and Ffield, 2008; Robertson, 2010; Nagai and Hibiya, 2015) and satellite altimetry for the barotropic tide (e.g., Egbert and Ray, 2000, 2003). Conversion rates from barotropic to baroclinic tides show that the Indonesian seas are one of the main regions for internal tide generation (Lyard and Le Provost, 2002) with a power value of $0.11 \mathrm{TW}$ that represents about $10 \%$ of the global power value (see as well Simmons et al., 2004). The strength of internal tides varies spatially depending on generation sites and interference patterns (e.g., Robertson, 2010; Rainville et al., 2010). As opposed to deep and large interior seas such as the Banda Sea, internal tides are enhanced within the small and shallow semi-enclosed seas as a result of numerous interactions between internal tidal beams originating from sills and shelf-slopes, wave-wave interactions and scattering (Robertson and Ffield, 2008; Buijsman et al., 2012; Mathur et al., 2014; Gayen and Sarkar, 2011). These differences in internal tide strength suggest 
that different mechanisms of energy transfers toward small scales are at play : weakly non linear wave-wave interactions of characteristic time scale much larger than the buoyancy period or more non-linear processes of smaller characteristic time scales.

The main objectives of the INDOMIX cruise were to estimate tidal mixing and provide a finescale parameterization of $\epsilon$ in this area. Koch-Larrouy et al. (2015) showed that tidal mixing is intensified in regions of rough topography and that subsurface mixing leads to significant surface cooling. They compared tidal mixing estimates from microstructure measurements and indirect estimates from geochemical tracers and finescale estimates from Thorpe scales all along the cruise path based on expandable bathythermograph, XBT, and conductivity-temperature-depth, CTD, measurements. None of the above mentioned studies focused on the relevance of finescale parameterizations of $\epsilon$ with direct observations of $\epsilon$. The use of repeated stations over two $M_{2}$ cycles at locations with contrasting internal tide energy levels makes this study a unique opportunity to closely examine the relevance of finescale parameterizations of $\epsilon$ using micro- and fine-structure observations of currents, temperature and salinity. These finescale parameterizations of $\epsilon$ induced by internal wave breaking rely on two key assumptions: firstly, that the turbulent kinetic energy results from an energy cascade toward small-scales driven by nonlinear wave-wave interactions, and secondly, that there is a balance between turbulent kinetic energy production, dissipation rate and buoyancy flux (e.g., Polzin et al., 2014). Hence, they do not apply to other situations that may lead to wave breaking such as boundary layer physics and hydraulic jumps or internal wave breaking resulting from a linear propagation in spatially inhomogeneous environments as underlined by Polzin 
et al. (2014). Moreover, applying the parameterization when turbulence is produced by strong nonlinear interactions may, in some cases, lead to underestimates of $\epsilon$, which can be crucial for large scale circulation issues (Polzin et al., 2014). The contrasting internal tide energy levels and the wide range of turbulence intensities of the INDOMIX measurements offer the opportunity to evaluate two main types of finescale parameterizations designed for different dynamical conditions. The first type is based on the assumption that energy is transferred toward small dissipative scales through a cascade initiated by weakly non-linear interactions between internal waves (e.g., McComas and Müller, 1981; Henyey et al., 1986). These formulations have been improved during the last decades as detailed in a recent review by Polzin et al. (2014). Alternatively, the second type of parameterization is designed for situations where one frequency constituent or low vertical mode dominates (MacKinnon and Gregg, 2003). This parameterization was first validated in a coastal area (MacKinnon and Gregg, 2003) and then in an open-ocean area in presence of strong internal tide (Xie et al., 2013). Our purpose is to evaluate the relevance of these finescale parameterizations in different energetic regimes and levels of turbulence as observed in the ITF using our set of dissipation rates based on microstructure data.

The outline is the following: we present the dataset and methods in section 2 followed by an overview of internal tides which introduces the different dynamical context of the stations, dissipation rate and vertical eddy diffusivity in section 3. In section 4, we test existing finescale parameterizations. We also show that, for strongly turbulent regions, the dissipation rate can be directly inferred from the observed horizontal velocity 
117

differences along the vertical direction. Finally, results are summarized and discussed in section 5 .

\section{DATA AND METHODS}

The INDOMIX cruise took place from 11th to 19th July 2010 during spring tides. The first three stations were occupied in the Halmahera Sea (Figure 1), a region of strong barotropic to baroclinic tidal conversion (e.g., Nagai et al., 2017). The first and third stations, $S_{1}$ and $S_{3}$, were located near straits where a strong internal tide generation is expected. The second station, $S_{2}$, was in a deeper region located $\sim 40 \mathrm{~km}$ away from any generation area. These three stations emphasized the contrast between near-field and intermediate-field areas. Station $S_{4}$, located far from any boundary and generation areas in a deep region of the Banda Sea, is the only far-field station. Station $S_{5}$ located in one of the most energetic area regarding internal tides, the Ombai Strait, is another near-field station (Figure 2).

\subsection{CTD and LADCP}

CTD measurements were obtained using a Seabird SBE911 instrument. Data were averaged over 1-m bins to filter out spurious salinity peaks. The salinity standard deviation 
between the CTD and the bottle samples was o.o1. The CTD temperature standard deviation was $0.002{ }^{\circ} \mathrm{C}$ according to Seabird factory calibration (Atmadipoera et al., 2017). Simultaneously, currents were measured from a broadband $300 \mathrm{kHz}$ RDI lowered acoustic Doppler current profiler (LADCP). LADCP data were processed using the Visbeck velocity inversion method (Visbeck, 2002) and provided vertical profiles of horizontal currents at $8 \mathrm{~m}$ resolution. At each station, except that in the Banda Sea (station $\mathrm{S}_{4}$ ), CTD/LADCP profiles were repeated over two semi-diurnal tidal cycles with a maximum time interval of 3 hours with microstructure profiles in between (see Figure 1 ). In addition, the ship was equipped with two ADCPs with frequencies $150 \mathrm{kHz}$ and $75 \mathrm{kHz}$. Data from the $75 \mathrm{kHz}$ ship-ADCP (SADCP) used in this study provided currents at a $15 \mathrm{~m}$ vertical resolution after processing.

\subsection{Dissipation rate from microstructure measurements and diffusivity estimates}

For each station, microstructure measurements were collected using a vertical microstructure profiler, VMP6ooo (see Table 1). The dissipation rate of turbulent kinetic energy $(\epsilon)$ was inferred from centimeter-scale shear measurements. Note that, depending on the VMP weights used for its descent, the averaged VMP fall rate varied from one station to the other, typically from $0.5 \mathrm{~m} \mathrm{~s}^{-1}$ within passages to $1 \mathrm{~m} \mathrm{~s}^{-1}$ at the Banda Sea station. Variations in the VMP fall rate within each profile were small, typically of the order of $1 \%$, except at the very end of the profile which was not considered in the analysis. $\epsilon$ was inferred from the variance of the shear within the inertial range, typically within meter 
to centimeter scales. The experimental spectrum was next compared to the empirical spectrum, the Nasmyth spectrum (Nasmyth, 1970), which enabled validation of the estimate of $\epsilon$ (e.g., Ferron et al., 2014). The noise level was below $10^{-11} \mathrm{~W} \mathrm{~kg}^{-1}$. $\epsilon$ was first computed over a $1 \mathrm{~m}$ depth interval and then smoothed with a 10-m moving average. A total number of 36 profiles unevenly distributed among stations was carried out (Table $1)$.

The diapycnal diffusivity $\left(\mathrm{K}_{z}\right)$ is commonly inferred from the kinetic energy dissipation rate using the Osborn (1980) relationship:

$$
\mathrm{K}_{z}=\Gamma \epsilon \mathrm{N}^{-2}
$$

where $\Gamma$ is a mixing efficiency defined as the ratio between the buoyancy flux and the dissipation rate, $\Gamma=-\frac{g}{\rho_{0}} \frac{\overline{\rho^{\prime} w^{\prime}}}{\epsilon}$ with $w^{\prime}$ and $\rho^{\prime}$ the vertical velocity and density fluctuations, and $\mathrm{N}$ is the buoyancy frequency. $\mathrm{N}$ was first computed from the sorted density profile, $\mathrm{N}=\sqrt{-\frac{g}{\rho_{0}} \frac{d \rho_{\text {sorted }}}{d z}}$, with $\mathrm{d} z=1 \mathrm{~m}$, and then smoothed using a 10-m moving average for consistency with ADCP data. Data from the VMP SBE sensors were used in most cases except when spurious measurements were obtained in which cases data from the rosette interpolated at the time of VMP profiles were taken as a substitute. $\mathrm{N}^{2}$ values below a threshold value of $10^{-7} \mathrm{~s}^{-2}$ were excluded for the computation of $\mathrm{K}_{z}$, I and finescale parameterization estimates, assuming a precision of $\sim 10^{-4} \mathrm{kgm}^{-3}$ for density. In mixing studies, $\Gamma$ is generally set to 0.2 , which corresponds to a critical flux Richardson number $R_{\text {crit }}=0.17$ (Osborn, 1980). Shih et al. (2005) and more recently Bouffard and Boeg- 
man (2013) examined the relevance of the Osborn relation as a function of turbulence intensity:

$$
\mathrm{I}=\frac{\epsilon}{v N^{2}}
$$

where $v$ is the molecular viscosity. This ratio is a measure of the relative importance of destabilizing effects (turbulence) and stabilizing effects (stratification and viscosity). Alternatively, in terms of time scales, it is the squared ratio of the buoyancy time scale $(1 / N)$ and the Kolmogorov time scale, namely the dissipation time scale of eddies at the Kolmogorov scale $(\sqrt{v / \epsilon})$. Shih et al. (2005) gave evidence of three regimes according to the I values: the energetic regime that corresponds to I $>100$, the intermediate regime for $7<\mathrm{I}<100$, and the diffusive regime for $\mathrm{I} \leqslant 7$ in which case the diffusivity reduces to the molecular value. Shih et al. (2005) showed in a numerical study that the Osborn relationship overestimated $K_{z}$ for the energetic regime $(I \geqslant 100)$ and proposed a new parameterization of $K_{z}$ for this regime. A few years later, Bouffard and Boegman (2013) proposed a refined parameterization of $\mathrm{K}_{z}$ based on in-situ microstructure measurements in lakes. They kept the three main regimes defined by Shih et al. (2005) but introduced two sub-regimes in the diffusive regime, a molecular regime for the smallest I values, $\mathrm{I}<1.7$, and a buoyancy-controlled regime, $1.7 \leqslant \mathrm{I} \leqslant 8.5$. The formulations of $\mathrm{K}_{z}$ for these regimes are given by:

- $\mathrm{K}_{z}=10^{-7} \mathrm{~m}^{2} \mathrm{~s}^{-1}$ within the diffusive sub-regime, $\mathrm{I}<1.7$

- $\mathrm{K}_{z}=\frac{0.1}{7^{1 / 4}} \gamma \mathrm{I}^{3 / 2}$ within the buoyancy controlled sub-regime, $1.7 \leqslant \mathrm{I} \leqslant 8.5$

- $\mathrm{K}_{z}=0.2 v \mathrm{I}$, i.e. the Osborn relationship within the intermediate regime, $8.5 \leqslant \mathrm{I} \leqslant$ 400 
- $\mathrm{K}_{z}=4 v \mathrm{I}^{1 / 2}$ within the energetic regime, $\mathrm{I}>400$

This parameterization is subject to controversy in the field measurement community (e.g., Gregg et al., 2012) who argued that the reduced mixing efficiency obtained in laboratory experiments and numerical simulations was an artefact. Their first concern dealt with the way turbulence was driven and the second to the fact that part of the downward transport from the outer scale was not resolved in the simulations since the size of the domain was of the same order as the Ozmidov scale which defines the upper bound of the inertial range. Bouffard and Boegman (2013) addressed these questions and showed that the Shih et al. (2005) parameterization held within a factor of 2 based on observations collected in lakes. The decrease in mixing efficiency with increasing turbulence intensity was also evidenced in the ocean (e.g., Bluteau et al., 2013). Hence, we applied the Bouffard and Boegman parameterization in this study while the Osborn estimate was computed for comparison.

\subsection{Internal tide generation and propagation}

\section{Linear approximation of the generating force for internal tide}

The internal tide generation was inferred from the generating force at the bottom following the linear approximation (e.g., Baines, 1982) that reads:

$$
\|\overrightarrow{\mathrm{F}}\|=\frac{\mathrm{N}^{2}}{\omega} \frac{\|\overrightarrow{\mathrm{Q}} \cdot \nabla \mathrm{h}\|}{\mathrm{h}}
$$

where $\mathrm{N}^{2}=2.9 \times 10^{-6} \mathrm{rad}^{2} \mathrm{~s}^{-2}, \omega$ is the tidal frequency, and $\|\overrightarrow{\mathrm{Q}}\|$ is the barotropic tidal flux and $h$ the depth. The barotropic tidal flux was inferred from the $1 / 30^{\circ} \times 1 / 30^{\circ}$ 
global inverse tidal model TPXO (Egbert and Erofeeva, 2002) for two main constituents, the diurnal $\mathrm{K}_{1}$ and the semi-diurnal M2.

\section{Idealized two-dimensional simulations}

Further insights on internal tides were inferred from a two-dimensional linear model of internal tide generation and propagation (Gerkema et al., 2004). The model assumed spatial uniformity in the direction perpendicular to the $2 \mathrm{D}$ vertical section while geostrophic currents were taken into account through the thermal wind balance. The model was applied and validated against in-situ measurements in the Bay of Biscay (Gerkema et al., 2004) as well as in the Mozambique channel where the influence of eddies on internal tide propagation is significant (Manders et al., 2004). The horizontal resolution was $400 \mathrm{~m}$ while in the vertical direction a Chebyshev collocation method was used involving 60 polynomial functions. The inputs for the model were the barotropic flux, the topographic profile along the section and the buoyancy field, N. The barotropic flux was prescribed at the boundaries using TPXO outputs for the semi-diurnal M2 and diurnal $\mathrm{K} 1$ constituents. The topographic profile was inferred from the Smith and Sandwell bathymetry and interpolated on the $400 \mathrm{~m}$ resolution grid of the model. The buoyancy field was inferred from in-situ data collected during the cruise: the time averaged $\mathrm{N}^{2}$ profile smoothed over a $30 \mathrm{~m}$ window was considered. The Gerkema's model was applied to the $2 \mathrm{D}$-section of the Halmahera Sea passing through stations $S_{1}, S_{2}$ and $S_{3}$. The model was also applied to a section passing through the Ombai strait. 


\subsection{Finescale parameterization}

In the absence of microstructure measurements, $\epsilon$ is classically inferred from a finescale parameterization which relates properties of the internal wave field to the energy dissipation rate. This relationship depends on the dynamics of the internal wave field that controls energy transfers toward small scales.

Typically, when the time scale of non-linear interactions is larger than the period of the waves, which is the case of an internal wave field close to the GM model, $\epsilon$ scales like $E^{2}$, where $E$ is the energy level of the internal wavefield. Different formulations have been proposed either as a function of energy, shear $\left(S=\sqrt{\left(\partial_{z} v_{x}\right)^{2}+\left(\partial_{z} v_{y}\right)^{2}}\right.$ with $v_{x}$ and $v_{y}$ the zonal and meridional velocity components) and/or strain $\left(\partial_{z} \zeta\right.$ with $\zeta$ the isopycnal displacement) (e.g., Gregg et al., 2003; MacKinnon and Gregg, 2003; Wijesekera et al., 1993). It is noteworthy to mention that these parameterizations applied to CTD/LADCP data are able to reproduce observed levels of $\epsilon$ within a factor of two for conditions close to the GM79 model (Gregg, 1989), a semi-empirical model of oceanic internal waves far from generation and dissipation area.

\section{GM-based Gregg- Henyey- Polzin model}

The parameterization proposed by Henyey et al. (1986) and extensively tested by Gregg (1989) reads:

$$
\epsilon_{\mathrm{G} 89}=7 \times 10^{-10}\left(\frac{\mathrm{N}^{2}}{\mathrm{~N}_{0}^{2}}\right)\left(\frac{\mathrm{S}^{4}}{S_{\mathrm{GM}}^{4}}\right)
$$


where $N_{0}$ is the canonical GM buoyancy frequency, $S$ is the shear of horizontal velocities and $S_{\mathrm{GM}}$ is the GM shear, with $\mathrm{S}_{\mathrm{GM}}^{4}=1.66 \times 10^{-10}\left(\mathrm{~N}^{2} / \mathrm{N}_{0}^{2}\right)^{2}$. The shear, $\mathrm{S}$, was first calculated in the spectral domain and then back-transformed to the physical domain after removing all wavelengths smaller than $16 \mathrm{~m}$ (Nyquist wavelength) and the buoyancy frequency $\mathrm{N}$ was averaged over $16 \mathrm{~m}$ for consistency. Data points with either $\mathrm{N}^{2}<10^{-7} \mathrm{~s}^{-2}$ and / or $S^{2}<10^{-7} \mathrm{~s}^{-2}$ were excluded from the computations to avoid spurious values affected by the noise level on $\mathrm{N}$ and / or $\mathrm{S}$ assuming a precision of $\sim 10^{-4} \mathrm{kgm}^{-3}$ for density and of $\sim 10^{-2} \mathrm{~ms}^{-1}$ for velocity. Equation (3) is based upon the assumption of a constant shear to strain ratio equal to that of GM. Polzin et al. (1995) showed that this ratio, $R_{\omega}$, was a function of the frequency content of the internal wave field. Thus, they introduced an additional factor to G89, $h\left(R_{\omega}\right)=3\left(R_{\omega}+1\right) /\left[2 \sqrt{2} R_{\omega} \sqrt{\left(R_{\omega}-1\right)}\right]$ (see as well Kunze et al., 2006; Gregg et al., 2003). Additionnally, a factor function of latitude was introduced by Gregg et al. (2003), leading to the most popular incarnation (e.g., Cuypers et al., 2012; Pasquet et al., 2016):

$$
\epsilon_{G H P}=\frac{f \cosh ^{-1}\left(\frac{N}{f}\right)}{f_{30} \cosh ^{-1}\left(\frac{N_{0}}{f_{30}}\right)} h\left(R_{\omega}\right) \epsilon_{G 89}
$$

For the repeated stations, a time-mean density profile was calculated from which strain and buoyancy frequency were calculated and subsequently filtered using a 10-m moving average and a mean $R_{\omega}=<S^{2}>/\left(<N^{2}><\zeta_{z}^{2}>\right)$ was inferred. For the station $S_{4}$ single profile, the isopycnal displacements were estimated from a reference stratification inferred from a $100-\mathrm{m}$ moving average of $\mathrm{N}^{2}$. In all cases, regions of low stratification and low shear, $\mathrm{N}^{2}<10^{-7} \mathrm{~s}^{-2}$ and/or $\mathrm{S}^{2}<10^{-7} \mathrm{~s}^{-2}$, were excluded.

We also tested one of the most recent formulation of the previous parameterization in 
which shear and strain variances are computed in spectral space using $320 \mathrm{~m}$ segments (e.g. Kunze et al., 2006), referred to as $\epsilon_{K 06}$. This method especially designed for deep profiles was extensively applied to infer the large scale structure of $\epsilon$ and $K_{z}$ using CTD and LADCP data surveys (e.g., Naveira Garabato et al., 2004; Walter et al., 2005; Kunze et al., 2006; Huussen et al., 2012; Waterman et al., 2013). $\epsilon_{\mathrm{K} 06}$ provides an averaged estimate of $\epsilon$ compared to $\epsilon_{\mathrm{GH}}$. Details of the method and results for $\epsilon_{\mathrm{K} 06}$ are shown in the appendix.

\section{Narrow-band internal wave spectrum}

MacKinnon and Gregg (2005) proposed a formulation that applies to an internal wave field dominated by a low-mode wave. In this case, they found that the energy dissipation rate scales like the low-frequency shear: $\epsilon \sim\left(\mathrm{N} / \mathrm{N}_{0}\right)\left(S_{\text {lf }} / S_{0}\right)$, with $S_{\text {lf }}$ the low mode shear. This scaling, originally developed for a coastal environment, was validated by Xie et al. (2013) in the deep Bay of Biscay in the presence of strong internal tides and a strong seasonal thermocline. Since our study region also exhibited a low wavenumber component in the background tidal shear, we followed Xie et al. (2013) and computed a modified MG formulation that reads:

$$
\epsilon_{M G}=\epsilon_{0}\left(\frac{N}{N_{0}}\right)\left(\frac{S}{S_{0}}\right)
$$

with $\epsilon_{0}$ is an adjustable parameter determined from VMP measurements equal to $2 \times$ $10^{-10} \mathrm{~W} \mathrm{~kg}^{-1}, \mathrm{~S}$ is the vertical shear computed in spectral space, low-pass filtered with 
$1 / 16 \mathrm{cpm}$ upper bound for vertical wavenumbers, and with $S_{0}=3 / 3600 \mathrm{~s}^{-1}$.

\subsection{Vertical shear spectra}

Vertical wavenumber shear spectra were computed for each LADCP profile and averaged by station (Figure 3). For each horizontal velocity profile, a periodic signal was constructed using symmetry properties (e.g. Canuto et al., 1988; Bouruet-Aubertot et al., 1995). The spectrum was computed using a rectangular window whose length equals the periodic signal. For comparison, two GM shear spectra are shown in Figure 3: the GM shear spectrum with its canonical shear variance and a GM spectrum fitted to the observed shear variance, which was computed in spectral space up to $k_{c}=1 / 100 \mathrm{cpm}$ (Figure 3, red and black dashed lines respectively). Shear spectra have a shape close to the GM shape (Garrett and Munk, 1975) for all stations (Figure 3, black curve) and roll-off beyond a critical wavenumber. The observed shear spectral level is an order of magnitude larger than the GM level at all stations except at station $S_{4}$ in the Banda Sea, which suggests that $\epsilon_{\mathrm{GHP}}$ should better predict $\epsilon$ at station $S_{4}$ than at the other stations. Note that a few peaks are present for stations $S_{1}$ and $S_{3}$ at small vertical wavenumbers. The strong dominance of diurnal and semi-diurnal tidal frequencies in the baroclinic signals plus the presence of peaks at low wavenumbers in the shear spectrum suggest that the internal wave field is dominated by low mode internal tides. Such properties are typical of the MG framework which gives an additional motivation to test the MG 
313

parameterization. Note that we do not see any signature of a white noise characterized by a $k_{z}^{2}$ dependency in the shear spectra indicating that the noise level is well below the physical shear variance at all shown wavenumbers. Another issue discussed by Polzin et al. (2002) is a possible high wavenumber attenuation of the shear spectrum resulting from the LADCP processing. The fact that we observe a GM shape below $k_{c}$ suggests that this attenuation is negligible here. Therefore we did not apply any spectral correction on the LADCP signal.

\section{A CONTRASTED SPATIAL DISTRIBUTION OF INTERNAL TIDES AND DISSIPATION RATE}

\subsection{Spatial distribution of internal tide energy from a linear model}

Several hot spots of internal tide generation are found in the Indonesian seas (Figure 2). The generating force exhibits very similar patterns for the two constituents $K_{1}$ and M2 (Figures 2a, b). As expected, the largest values are found within straits and over the shelf slopes since these regions are both characterized by strong barotropic currents and significant slopes. The map of the generating force in the Halmahera Sea (Figure 2) gives evidence of the contrast between stations $S_{1}$ and $S_{3}$, which are both located in generation areas (near-field), and station $S_{2}$ located further away in deeper waters (intermediate field). Station $S_{4}$ in the Banda Sea is far from any generation area (far-field) 
while station $S_{5}$ in the Ombai Strait is in a generation area (near-field).

The linear internal tide model was applied to a section passing by stations $S_{1}, S_{2}$ and $S_{3}$ in the Halmahera Sea and to a section crossing the Ombai Strait. Since the barotropic tidal flux at these stations is close to the direction of the modeled section (Figure 2), the idealized $2 \mathrm{D}$-simulations are expected to give a first-order view of the true internal tidal field in this area. Internal tidal rays generated at a few topographic features undergo succcessive reflections at the surface and at 30o-60om, leading to an enhanced internal tide signal almost uniformly along the section in the upper three hundred meters (Figure $4 \mathrm{a}, \mathrm{b})$. Deeper, below $\sim 600 \mathrm{~m}$ depth, the variation in internal tide amplitude is striking with strong currents near generation regions and weak currents elsewhere except locally near the bottom. The linear model predicts large internal tide energy levels over the entire water column at station $S_{3}$ and to a lesser extent at station $S_{1}$, while large values are confined within the upper four hundred meters at station $S_{2}$ located further away from a generation area. Based on this pattern, we expect to observe a strong internal tide signal in the velocity and density fields at those three stations. A strong tidal signal is generated at station $S_{5}$ located near the sill of the Ombai Strait (Figure $4 b, d$ ). There, the modeled internal tide signal is confined at depth within a few hundreds meters above the bottom where both $\mathrm{M} 2$ and $\mathrm{K} 1$ internal rays superimpose. 


\subsection{Spatial distribution of internal tide energy from observations}

The vertical and horizontal distribution of internal tide energy was diagnosed from the CTD-LADCP stations. The four stations with repeated profiles over two semi-diurnal periods provided us with time-depth sections of meridional currents (Figure 5, left-hand panels). The meridional component of the total current reaches velocities up to $1.3 \mathrm{~m} \mathrm{~s}^{-1}$, $0.7 \mathrm{~m} \mathrm{~s}^{-1}, 1 \mathrm{~m} \mathrm{~s}^{-1}$ and $1.4 \mathrm{~m} \mathrm{~s}^{-1}$ at stations $S_{1}, S_{2}, S_{3}$ and $S_{5}$ respectively. The strongest currents are observed in the Ombai Strait $\left(S_{5}\right)$ and at the entrance of the Halmahera Sea $\left(S_{1}\right)$ and to a lesser extent at the Southern passage of the Halmahera Sea $\left(S_{3}\right)$. Currents are significantly weaker at station $S_{2}$ (and at station $S_{4}$ with a maximum value of $0.4 \mathrm{~m} \mathrm{~s}^{-1}$, not shown). This station, located in a deeper area compared to stations $\mathrm{S}_{1}$ and $S_{3}$, is away from generation areas (Figure $1 b$ ). The tidal component of the currents is further evidenced by the perturbation of the baroclinic current, i.e. the baroclinic current minus its time average, typically over two M2 periods (i.e. $\vec{v}^{\prime}=\overrightarrow{v_{\mathrm{bcl}}}-<\overrightarrow{v_{\mathrm{bcl}}}>$ with $\overrightarrow{v_{\mathrm{bcl}}}=\vec{v}-1 / \mathrm{H} \int_{0}^{\mathrm{H}} \vec{v} \mathrm{~d} z$ )( Figure 5, right-hand panels). All stations, except station $\mathrm{S}_{2}$, exhibit strong currents $\left(\sim 1 \mathrm{~m} \mathrm{~s}^{-1}\right)$ and large isopycnal displacements of a few hundred meters at depth. Semi-diurnal and diurnal periods are easily identified: at $600 \mathrm{~m}$ at station $S_{1}$ and around 500-80om at station $S_{3}$ for the semi-diurnal component, and at 100 $m$ depth at station $S_{1}$ for the diurnal component. Vertical propagations are evidenced in some cases: downward phase propagation at stations $S_{2}$ and $S_{3}$, both downward and upward phase propagation at stations $S_{1}$ and $S_{5}$. The diurnal and semi-diurnal constituents contribute more than $58 \%$ to the total variance. 
SADCP data collected in the Halmahera Sea along the section corresponding to the $2 \mathrm{D}$ linear simulations show strong currents at station $S_{1}$ and to a lesser extent at station $S_{3}$, and weak currents at station $S_{2}$ (Figure 6a). The SADCP time series at the stations better highlights the contrast in current magnitudes between stations (Figure 6b). The contrast in the vertical shear of horizontal velocities is less obvious, as a result of the fairly coarse, $15 \mathrm{~m}$, vertical resolution of the $75 \mathrm{kHz}$ SADCP, but still evident (Figure 6c). The propagation of sharp localised bands of strong shear, resembling that of internal tidal rays in the model, is nicely evidenced in the time series of Figure $6 c$.

The linear internal tide model (Gerkema et al., 2004) is consistent with velocity and density observations: a weak internal tide energy is found at station $S_{2}$ while larger ones are found at stations $S_{1}, S_{3}$ and $S_{5}$ (Figure 4, Figure 5.c and d, Figure 6). At the energetic stations, $S_{1}, S_{3}$ and $S_{5}$, the topography is supercritical toward diurnal and semi-diurnal tides (i.e. the topography is steeper than the internal tidal beams leading to both up and down scattering), which corresponds to the 'tall topography' case with a tidal excursion smaller than one (e.g., Legg and Huijts, 2006) that favors internal tide generation (Figure 4). If strong enough, the barotropic flow can locally trap baroclinic internal wave modes, thus reinforcing nonlinearities in the vicinity of generation areas such as stations $S_{1}, S_{3}$ and $S_{5}$. Interestingly, this linear model gives a preliminary insight in the context despite it ignores the three dimensional propagation of internal waves, non-linearities in the dynamics and the impact of the barotropic current on internal wave propagation (e.g. Lelong and Dunkerton, 1998a,b; Lelong and Kunze, 2013). 


\subsection{Contrasting profiles of turbulent kinetic energy dissipation rates}

The largest $\epsilon$ are observed at stations $S_{1}$ and $S_{5}$ with intense turbulence throughout the water column (Figure 7, colored profiles). These large values of $\epsilon$ are most often correlated with large isopycnal displacements and strain at depth (Figures $7 \mathrm{a}, \mathrm{d}$, black lines) and occasionally with strong shear (Figures $7 \mathrm{a}, \mathrm{d}$, magenta background). Spots of large $\epsilon$ are observed at station $S_{3}$ with periods of weaker turbulence (especially for time within $[4-9] \mathrm{h}$, Figure $7 \mathrm{c})$. In contrast, $\epsilon$ is typically smaller by more than one order of magnitude at station $S_{2}$ compared with the other stations, which is consistent with the weaker amplitude both in shear and strain.

Time-averaged profiles of dissipation rates $\epsilon$ and of diapycnal diffusivity $\mathrm{K}_{z}$ highlight the contrast in small-scale turbulence between the stations (Figure 8a, b). The largest $\epsilon$ are observed close to internal tide generation areas (stations $S_{1}, S_{3}$ and $S_{5}$ ). The depthaveraged $\epsilon$ reached $9.8 \times 10^{-6} \mathrm{~W} \mathrm{~kg}^{-1}$ at station $S_{5}$ in the Ombai Strait, $4.9 \times 10^{-7} \mathrm{~W} \mathrm{~kg}^{-1}$ at station $S_{1}$ and $2.8 \times 10^{-7} \mathrm{~W} \mathrm{~kg}^{-1}$ at station $S_{3}$ in the Halmahera Sea. In contrast, far from generation areas, in the Banda Sea at station $S_{4}, \epsilon$ is smaller by several orders of magnitude below $100 \mathrm{~m}$ depth. Eventually, a few tens of kilometers away from generation areas, an intermediate depth-averaged $\epsilon$ of $9 \times 10^{-9} \mathrm{~W} \mathrm{~kg}^{-1}$ is obtained at station $S_{2}$ (see Table 2). Averaging $\epsilon$ over the thermocline instead of the full-depth decreases the range of variations to a factor of 4 between the stations within straits $\left(S_{1}>S_{5}>\right.$ $S_{3}$ ), and to a factor of 2 between stations $S_{2}$ and $S_{3}$ (see Table 3). These variations of $\epsilon$, weaker in the thermocline than at depth, are consistent with the linear tidal model 
that shows much larger tidal currents in the thermocline than at depth. Interestingly, we note an increase in $\epsilon$ in the bottom $100 \mathrm{~m}$ (e.g. Figure 8a, station $S_{2}$ ), with values up to $\sim 10^{-8} \mathrm{~W} \mathrm{~kg}^{-1}$, which might be a signature of the stratified bottom boundary layer (e.g., St Laurent and Thurnherr, 2007).

As with $\epsilon$, time-averaged profiles of $K_{z}$ show that the largest values are located at stations $S_{1}, S_{5}$ and $S_{3}$, and the smallest at station $S_{4}$ (Figure $8 b$ ). The contrast is striking between the intense mixing within passages, with a depth- and time-averaged $\mathrm{K}_{z}$ of $1.9 \times 10^{-3} \mathrm{~m}^{2} \mathrm{~s}^{-1}, 9.4 \times 10^{-4} \mathrm{~m}^{2} \mathrm{~s}^{-1}$ and $3.7 \times 10^{-4} \mathrm{~m}^{2} \mathrm{~s}^{-1}$ for stations $S_{5}, S_{1}$ and $S_{3}$ respectively, and that of the Banda Sea located away from any generation area with a $K_{z}$ of only $0.12 \times 10^{-4} \mathrm{~m}^{2} \mathrm{~s}^{-1}$. In the thermocline, mean $\mathrm{K}_{z}$ values range from $1.8 \times 10^{-5} \mathrm{~m}^{2} \mathrm{~s}^{-1}$ at station $S_{4}$ in the Banda Sea to $1.7 \times 10^{-4} \mathrm{~m}^{2} \mathrm{~s}^{-1}$ at station $S_{1}$ in the northern Halmahera passage. In the thermocline of the Halmahera Sea (stations $S_{1}, S_{2}$ and $S_{3}$ ), mean $\mathrm{K}_{z}$ values only vary within a factor of 10 , thus following the homogeneity in the mean $\epsilon$. Statistics of $\epsilon$ and $K_{z}$ are summarized in Tables 2 and 3. The Osborn formulation of $K_{z}$ is shown for comparison in Figure 8c. The estimates differ by two orders of magnitude at depth where turbulence intensity is strong, up to $10^{7}$. This points out the sensitivity of mixing estimates of water masses depending on the $K_{z}$ parameterization in regions of strong turbulence intensity as outlined by Shih et al. (2005).

As previously mentioned, the turbulence intensity is a relevant and important parameter to characterize the dynamics and the regime of turbulence, especially since turbulence is strongly intermittent and spatially heterogenous. The turbulence intensity, I 
(Eq.(2)), associated with the repeated profiles at each station were calculated and averaged in time (Figure 9). Vertical profiles of the percentage of occurrences of $I \leqslant 1000$ were calculated (Figure 9, red lines). I is always smaller than 1000 for the single profile of station $\mathrm{S}_{4}$ except in the upper $100 \mathrm{~m}$. In contrast, station-mean I-values are in the strongly energetic regime, I $>1000$, for stations $S_{1}$ and $S_{5}$, except in the upper $100 \mathrm{~m}$ and $200 \mathrm{~m}$, respectively. Station $S_{3}$ shows a region of moderate station-mean I-value, of the order of 500, in the upper $300 \mathrm{~m}$. Then strongly turbulent regimes increase from about $10-30 \%$ above the $300 \mathrm{~m}$ transition depth to $80 \%$ below. Station $\mathrm{S}_{2}$ mean I-values are typically within $[\sim 100 ; \sim 1000]$ except in the last hundred meters where strongly turbulent regime prevails.

We next examine whether these variations in I are consistent with that of the stationmean profiles of baroclinic tidal energy (kinetic and available potential). Tidal energy is the largest at stations $S_{1}$ and $S_{5}$, intermediate at station $S_{3}$, and the smallest at station $S_{2}$. This evolution is consistent with the overall variations of $\epsilon$ at the different stations. A more detailed comparison reveals that the contrast between stations evolves as a function of depth (Figure 10). In the first hundred meters, the tidal energy is of the same order of magnitude for all stations, consistently with $€$ (Figure 8a). Deeper, there is an increasing contrast between station $S_{2}$ and the three others: both $\epsilon$ and the tidal energy decrease significantly between 350 and $800 \mathrm{~m}$ at station $S_{2}$. Eventually, for the deepest levels, there is an increase in tidal energy that is also correlated with that of $\epsilon$. At the other stations, a correlation between $\epsilon$ and $E_{t}$ is obtained below $300 \mathrm{~m}$ at station $S_{1}$, and locally around $700 \mathrm{~m}$ depth at station $S_{5}$. In some cases, when variations of $\epsilon$ are not correlated 
with those of tidal energy, for instance at station $S_{3}$ between $\sim 300 \mathrm{~m}$ and $\sim 700 \mathrm{~m}$, they are correlated with the shear (non tidal). Note that processes other than internal tides such as internal solitary waves might possibly come into play here, especially within passages where huge isopycnal displacements are observed as for stations $S_{1}, S_{3}$ in the Halmahera Sea and station $S_{5}$ in the Ombai strait.

\section{LOOKING FOR A FINESCALE PARAMETERIZATION OF IN- TERNAL TIDAL MIXING}

\subsection{Test of finescale parameterizations}

In this set of stations with contrasting dissipation rates and turbulence intensities, finescale parameterizations, $\epsilon_{\mathrm{GHP}}$ and $\epsilon_{\mathrm{MG}}$, are compared against VMP measurements (Figure 1I). $\epsilon_{\mathrm{GHP}}$ reproduces reasonably well $\epsilon_{V M P}$ at station $S_{4}$ (Figure IId) which is located far from any internal tide generation area and with a weak atmospheric forcing. As a result the shear level is close to the GM value and nonlinear interactions are weak, falling into the domain of validity of the GHP parmeterization. At the other stations, where the internal tides are more energetic, $\epsilon_{\mathrm{GHP}}$ strongly underestimates $\epsilon_{\mathrm{VMP}}$ by at least one order of magnitude. This is somewhat expected since $\epsilon_{\mathrm{GHP}}$ is meant for an internal wave field close to GM levels, while, at these stations, observed shear levels are ten-fold larger than 
GM levels (Figure 3).

Contrastingly, $\epsilon_{M G}$ better predicts $\epsilon_{V M P}$ when the shear level is significantly higher than the GM value. It provides a relevant estimate at station $S_{2}$ (Figure 11 ) and in the upper part of the water column at stations $S_{1}, S_{3}$ and $S_{5}$ (Figure 11a, c, e).

Interestingly, regions where $\epsilon_{M G}$ better fits $\epsilon_{V M P}$ seem related to regions of moderate turbulence intensities. In order to determine if a threshold value of I bounds the domain where $\epsilon_{M G}$ is a relevant estimate of $\epsilon_{V M P}, \epsilon_{M G}$ is compared with $\epsilon_{V M P}$ as a function of turbulence intensities (Figure 12). There is a striking difference between station $S_{2}$, marked by moderate turbulence intensities for which $\epsilon_{M G}$ is fairly relevant, and stations $S_{1}, S_{3}$, and $S_{5}$ marked by strong turbulence intensities for which $\epsilon_{M G}$ clearly underestimates $\epsilon_{V M P}$. I is typically smaller than 1000 at station $S_{2}$ over most of the water column. At the energetic stations, $S_{1}, S_{3}$ and $S_{5}$, I is also smaller than 1000 in the first few hundred meters and sharply increases below (see for instance the transition around $300 \mathrm{~m}$ at station $S_{3}$, Figure $\left.9 \mathrm{c}\right)$. $\epsilon_{\mathrm{MG}}$ starts to deviate from $\epsilon_{\mathrm{VMP}}$ around this transition in I values. $\epsilon_{M G}$ largely underestimates $\epsilon_{V M P}$ at depth where strong turbulent regime prevails (I > 1000), which suggests that either strong non-linear wave-wave interactions or other processes than instabilities related to internal waves come into play. Finally, at station $S_{4}$ for which $\mathrm{I}<100, \epsilon_{M G}$ overestimates $\epsilon_{V M P}$ (Figure 11d). Thus, this data set suggests that for weakly turbulent regime $(\mathrm{I}<100), \epsilon_{\mathrm{GHP}}$ is the most appropriate; for moderate turbulent regime $(100<\mathrm{I}<1000), \epsilon_{M G}$ is the most appropriate; while for strong turbulent regime $(\mathrm{I}>1000)$ none of these parameterizations are relevant. 
Turbulence is often characterized by stabilizing (stratification, N) and destabilizing (vertical velocity shear, S) forces. In order to get more physical insight in the parameterization of $\epsilon$, we next compare their properties to those of $\epsilon_{\mathrm{VMP}}$ in $\left(S^{2}, \mathrm{~N}^{2}\right)$ space (Figure 13a-d). If turbulence is shear-induced, large dissipation rates are expected in regions of low Richardson number, $\mathrm{Ri}=\mathrm{N}^{2} / \mathrm{S}^{2}$. The following regions where either $\epsilon_{\mathrm{GHP}}$ or $\epsilon_{M G}$ provide a reasonable estimate of $\epsilon_{V M P}$ according to the station-mean dissipation rate profiles were selected (Figure 11): the whole profiles of $\epsilon_{M G}$ at station $S_{2}$ and $\epsilon_{G H P}$ at station $S_{4}$ and the upper $300 \mathrm{~m}$ of $\epsilon_{M G}$ at station $S_{3}$. At station $S_{2}$, the largest values of $\epsilon_{\mathrm{VMP}}$ are obtained for large shear and strong stratification of the thermocline (Figure 13a). $\epsilon_{M G}$ is able to reproduce this observed property (Figure 13d). Similarly, the pattern of $\epsilon_{M G}$ is close to that of $\epsilon_{V M P}$ in the first $300 \mathrm{~m}$ at station $S_{3}$ (Figure $13 \mathrm{~b}$ and e). At station $S_{4}$ in the Banda Sea, the pattern of $\epsilon_{V M P}$ with low values in the regions of strongest shear and stratification and large values for low $\mathrm{Ri}$ is well reproduced by $\epsilon_{\mathrm{GHP}}$ (Figure $13 \mathrm{C}$ and $\mathrm{f}$ ). This shows the fundamental difference between $\epsilon$ dependency in $\left(\mathrm{N}^{2}, \mathrm{~S}^{2}\right)$ space as a function of turbulence intensity (i.e. weakly nonlinear interactions for $\mathrm{I}<100$ and more nonlinear regimes for $100<\mathrm{I}<1000)$ and the relevance of $\epsilon_{\mathrm{GHP}}$ and $\epsilon_{M G}$ respectively to reproduce this pattern. 


\subsection{Estimate of turbulent kinetic energy dissipation rate in regions of strong turbulent intensity}

Finescale parameterizations are used to estimate the dissipation rates based on the properties of the internal wavefield with the assumption that internal waves weakly interact. Such parameterizations are expected to be relevant for weakly to moderately strong nonlinear interactions, but not necessarily for more non-linear wave dynamics, or stratified turbulence. Furthermore, the finescale parameterisations assume that the velocity shear and strain are indeed representative of the internal wave field. To get insights in the dynamical regime resolved with CTD/LADCP measurements, we look at the length scales that bound the inertial range of ${ }_{3} D$ turbulence, namely the Ozmidov scale $L_{O}=\sqrt{\epsilon / N^{3}}$ and the Kolmogorov scale $\mathrm{L}_{K}=\left(v^{3} / \epsilon\right)^{1 / 4}$ (Figure ${ }_{14}$ ). $\mathrm{L}_{\mathrm{O}}$ defines the vertical displacement resulting from the full conversion of the turbulent kinetic energy into available potential energy, it corresponds to the maximum scale of eddies within the inertial range while $L_{K}$ is the scale at which the turbulent kinetic energy is dissipated into heat. The Ozmidov scale varies widely from a few $\mathrm{cm}$ up to $\sim 100 \mathrm{~m}$. The smallest scales are reached in the thermocline and the largest at the deepest depths. The vertical LADCP bin size, $\Delta z=8 \mathrm{~m}$, is shown for comparison. When $\mathrm{L}_{\mathrm{O}}>\Delta z$, LADCP measurements fall in the inertial range in an averaged sense. Thus, a velocity difference calculated over a scale $\Delta z, \delta v=|\overrightarrow{v(z+\Delta z)}-\overrightarrow{v(z)}|$, is expected to follow the Kolmogorov scaling only when $\mathrm{L}_{\mathrm{O}}>\Delta z$. A significant part of stations $S_{1}, S_{3}$ and $S_{5}$ profiles fall into the inertial range since $\mathrm{L}_{\mathrm{O}}>\Delta z$ for height above the bottom smaller than $600 \mathrm{~m}, 400 \mathrm{~m}$ and $800 \mathrm{~m}$ respec- 
tively. In this range, the Kolmogorov theory predicts that the dissipation rate is given by $\epsilon_{I R}=\delta v^{3} / l$ within a factor of order 1 , where $\delta v$ is the velocity difference at scale $l$ (e.g., Tennekes and Lumley, 1972). A similar approach is adopted in the large eddy method, LEM, which is based on a scaling of the turbulent kinetic energy equation (Taylor, 1935) using a pragmatic approach to determine the 'transition' scale between fine-scale and turbulent motions and infer the turbulent kinetic energy (e.g. Moum, 1996; Peters et al., 1995; Beaird et al., 2012). Using $l=\Delta z=8 \mathrm{~m}, \epsilon_{\mathrm{IR}}$ was compared with $\epsilon_{\mathrm{VMP}}$ to check its relevance (Figure 15 ). There is generally a relatively good correspondance between $\epsilon_{\mathrm{VMP}}$ and $\epsilon_{\mathrm{IR}}$ provided that the averaged Ozmidov scale is larger than $\sim 8 \mathrm{~m}$. Several reasons possibly contribute to errors in the estimate of $\epsilon_{I R}$. Firstly, the assumption of ${ }_{3} D$ homogeneous and isotropic turbulence is not necessarily fulfilled. If not this will impact both the estimate of $\epsilon_{V M P}$, inferred from the components of the vertical shear only, and the rate of energy transfers inferred from vertical velocity differences. Secondly, in some cases, the time averaged values of $\epsilon_{V M P}$ and $\epsilon_{I R}$, that take into account between 5 to 12 profiles, are strongly influenced by 1 or 2 very large values such as at station $S_{5}$. The ability of $\epsilon_{I R}$ to predict $\epsilon_{V M P}$ within a factor of 10,5 and 2 was computed for regions such that $\mathrm{L}_{\mathrm{O}}>8 \mathrm{~m}$ (Table 4 ). In all cases, except at station $\mathrm{S}_{2}$, more than $75 \%$ of the ratio $\epsilon_{\mathrm{IR}} / \epsilon_{\mathrm{VMP}}$ falls within a factor of 2. 


\section{SUMMARY AND DISCUSSION}

Microstructure measurements gave evidence of the contrast between the very large dissipation rates encountered in passages and those, still large but smaller, measured in deeper regions further away from generation areas of internal tides (see as well KochLarrouy et al., 2015). Depth averaged dissipation rates varied by 4 orders of magnitude over the whole water column and by 2 orders of magnitude in the thermocline. This distribution was explained by the presence of strong barotropic and baroclinic tidal currents within passages, whereas the internal tidal signal is more confined within the thermocline for stations further away from any generation area. Note that baroclinic near-inertial waves may also contribute to the enhanced internal wave signal in the upper few hundred meters as previously evidenced by Alford et al. (1999) in the Banda Sea. Their cruise was held in October, a few weeks after the strong summer monsoon winds that led to the generation of the observed baroclinic near-inertial wave. The INDOMIX cruise was held in July during the strong summer monsoon winds period that favors the generation of energetic baroclinic near-inertial waves. It is hypothezised that the energetic baroclinic near-inertial waves, that may have been induced by the strong winds observed during the cruise in the Banda Sea and in the Ombai strait, were not sampled since their propagation at depth is typically observed within a few weeks after the strong summer wind period (e.g., Alford et al., 1999). In any case, it was not possible to characterize baroclinic near-inertial waves with our one day measurements since the inertial period was at least of 3.5 days. Maximum $K_{z}$ values in the thermocline, where most 
water mass transformations occur, ranged from $2 \times 10^{-3} \mathrm{~m}^{2} \mathrm{~s}^{-1}$ down to $7 \times 10^{-4} \mathrm{~m}^{2} \mathrm{~s}^{-1}$, which is consistent with integrated estimates from water mass transformations (Ffield and Gordon, 1992). In regions of strong turbulent intensity, the Osborn parameterization overestimated the mean $K_{z}$ by a factor of $\sim 50$ compared to the Bouffard parameterization as mixing efficiency decreases with increasing turbulent intensity. The consequence on watermass transformation should be significant in the Indonesian Seas, as already pointed out in a numerical study at global scale by De Lavergne et al. (2016a) and more specifically for the Antarctic Bottom Water by De Lavergne et al. (2016b).

Turbulence intensity, indicative of non-linearities in the internal wave field, ranged from $\sim 7$ up to $10^{7}$. Hence, this dataset shows that different processes at the origin of the energy cascade toward small scales are expected depending on the regime of turbulence intensity: in the weakly turbulent regime $(\mathrm{I}<100)$, the internal wave field is close to GM and marked by weakly non linear interactions; in the moderately turbulent regime $(100<\mathrm{I}<1000)$, an energetic dominant internal tide is found with an internal wave energy level ten-fold larger than the GM level; in the strong turbulent regime (I > 1000) that prevails near sills, non-linear waves, convectively unstable, are expected as observed by van Haren et al. (2015), leading to direct energy transfers toward smallscales (e.g. Lelong and Dunkerton, 1998a,b). The presence of large barotropic currents also suggested possible wave trapping of high baroclinic modes with upstream phase propagation. However the exact nature of the processes involved was however difficult to assess as we lack cross-sill measurements. 
In this very specific situation of highly variable internal wave energy levels, two fine-scale parameterizations were tested: the Gregg-Henyey-Polzin parameterization designed for internal wave fields close to GM, and that proposed by MacKinnon and Gregg (2003) which was validated for non GM internal wave fields (e.g. Xie et al., 2013). Far from generation areas, in the 'far-field' region characterized by shear levels close to the GM level and weak turbulence intensities, $\epsilon_{\mathrm{GHP}}$ and $\epsilon_{\mathrm{K} 06}$ formulations of the GreggHenyey-Polzin parameterization provided a relevant estimate of $\epsilon$. In the Halmahera Sea and the Ombai Strait where the shear level is larger, MG parameterization provided a relevant estimate of $\epsilon$ for moderate turbulence intensities. In the strongly nonlinear regimes, for which none of these parameterizations applied, stratification effects are negligible and the Kolmogorov scaling of epsilon inferred from velocity differences, $\epsilon_{I R}$, provided a relevant estimate of the dissipation rate when the vertical resolution of CTD/LADCP measurements fell into the inertial range domain. Our results are consistent with previous findings based on a simple $\epsilon$ scaling function of the turbulent kinetic energy, i.e. the large eddy method, LEM, which was found of relevance provided that scales smaller than overturning scales are resolved (e.g., Moum, 1996; Peters et al., 1995; Beaird et al., 2012).

Some guidelines for a practical procedure to infer finescale estimates of $\epsilon$ can be drawn from this study though more work with a larger dataset would be required for refined conclusions. This procedure requires three stages. Firstly, the comparison with the GM shear spectra should be performed: whether the observed shear spectra are close both in shape and level to the GM shear spectra or not will determine if the Gregg-HenyeyPolzin parameterization applies. If these conditions are not fulfilled, but if instead a few 
low modes are observed, the MG parameterization should apply provided that the shear level remains within a factor of 10 of the GM shear level. For the strongest turbulent regimes, typically encountered near generation areas for internal tides, the Kolmogorov scaling $\left(\epsilon_{I R}\right)$ appears to be the most relevant provided that part of the vertical scales of velocity measurements fall within the inertial subrange, which can be inferred from Thorpe scales.

This dataset raises the question of the scaling of the dissipation rate for more strongly non-linear regimes that correspond to turbulence intensities larger than $\sim 1000$. Several studies focused on the parameterization of the dissipation rate over sills where the internal tide regime dominates (e.g., Klymak et al., 2010; Legg and Huijts, 2006). For instance Klymak et al. (2010) proposed an estimate of dissipation rate from the barotropic tidal power conversion into trapped baroclinic modes in the case of a knife-edge topography Llewellyn Smith and Young (2003). This parameterization was tested within the Ombai strait but this seemed a too ambitious goal owing to the lack of measurements across the sill. A dedicated survey with fine- and micro-structure measurements across the passage, including the main generation area at the sill, would enable validation of a parameterization of dissipation rate and to compute the energy flux of trapped baroclinic modes.

\section{Acknowledgment}

We thank the chief scientist, Ariane Koch-Larrouy, and Hélène Leau from IPEV for their support during the cruise and Robert Molcard for his numerous advices. We warmly acknowledge the assistance of the crew of the french research vessel Marion-Dufresne, 
during the deployement of the VMP. We thank Claudie Marec and Jacques Grelet for their technical support for the CTD-LADCP and for post-processing these data as well as Annie Kartavtseff for processing the SADCP data. This work was financially supported by LEFE-IDAO and additional funding by LOCEAN. The microstructure profiler was funded by the French Agence Nationale de la Recherche (ANR) through the ANR-JCo550690 grant and part of the functionning expenses by the French Institute for Marine Science (IFREMER). The INDOMIX cruise is a collaborative research between France and Indonesia. Agus Atmadipoera was funded in part by a grant from the Ministry Education National (DIKTI), through contract 591.11/I3/11/PL/2010.

\section{APPENDIX: TEST OF ONE OF THE KUNZE ET AL (2006)}

\section{PARAMETERIZATION}

We applied the procedure described by Kunze et al. (2006) with additional details provided in Pasquet et al. (2016). The vertical eddy diffusivity is inferred from the shear and strain variances computed using a spectral method upon vertical segments of $320 \mathrm{~m}$ for the shear and $256 \mathrm{~m}$ for the strain with an overlap of $160 \mathrm{~m}$. Following Kunze et al. (2006) we first compute diapycnal diffusivity, $K_{K 06}$ which is given by:

$$
K_{\mathrm{Ko6}}=\mathrm{K}_{0} \frac{\left\langle\mathrm{S}^{2}\right\rangle^{2}}{\left\langle\mathrm{~S}^{2}\right\rangle_{\mathrm{GM}}^{2}} \mathrm{j}(\mathrm{f} / \mathrm{N}) \mathrm{h}\left(\mathrm{R}_{\boldsymbol{\omega}}\right)
$$


663

$S^{2}$ is the shear variance which is obtained by integrating the shear spectrum on the vertical wavenumber interval $\left[\frac{2 \pi}{320} \mathrm{rad} \mathrm{m}^{-1} ; \mathrm{k}_{\mathrm{c}}\right]$ where $\mathrm{k}_{\mathrm{c}}$ is equal to the minimum wavenumber between the default value $\frac{2 \pi}{16} \mathrm{rad} \mathrm{m}^{-1}$ and the wavenumber at which the signal to noise ratio is equal to 5 (see Pasquet et al. (2016) for details); the other terms are defined as follows:

$$
\begin{aligned}
K_{0} & =5 \times 10^{-6} \mathrm{~m}^{2} \cdot \mathrm{s}^{-1} \\
j(f / N) & =\frac{f \cosh ^{-1}(\bar{N} / f)}{f_{30} \cosh ^{-1}\left(N_{0} / f_{30}\right)}
\end{aligned}
$$

$f$ is the Coriolis parameter, $f_{30}$ is the Coriolis value at $30 N,(8)$ takes into account the variation with latitude (Gregg et al., 2003) and $\bar{N}$ is the buoyancy frequency averaged over the $320 \mathrm{~m}$ length segment. Note that we have taken into account in our calculation the corrections of LADCP shear proposed by Polzin et al. (2002) and Thurnherr et al. (2012) (see Pasquet et al., 2016, for further details).

Dissipation rate is then inferred as:

$$
\epsilon_{\mathrm{Ko6}}=5 \mathrm{~K}_{\mathrm{Ko6}} \overline{\mathrm{N}}^{2}
$$

$\epsilon_{\mathrm{Ko6}}$ was compared at all stations with $\epsilon_{v m p}$ which was averaged over the computations intervals of $\epsilon_{\mathrm{K} 06}$ for consistency (Figure 16). $\epsilon_{\mathrm{K} 06}$ predicts well dissipation rates at station $S_{4}$, with a mean $\epsilon_{\mathrm{Kob}} / \epsilon_{v m p}$ ratio equal to 2, while it underestimates $\epsilon_{v m p}$ at all the other stations with a mean $\epsilon_{\mathrm{Kob}} / \epsilon_{v m p}$ ratio varying from $3 \times 10^{-4}$ at station $S_{1}$ to $7 \times 10^{-2}$ at station $S_{2}$. These results show a close similarity between $\epsilon_{\mathrm{K} 06}$ and $\epsilon_{\mathrm{GHP}}$ namely a good agreement with $\epsilon_{v m p}$ when the shear level is comparable to the GM value. A closer comparison between these two formulations that mainly differ in the computation method is 
displayed in Figure 16 with $\epsilon_{\mathrm{GHP}}$ averaged over the $320 \mathrm{~m}$ computation interval of $\epsilon_{\mathrm{K} 06}$. The two formulations are consistent at all stations with a mean ratio between $\epsilon_{\mathrm{K} 06}$ and $\epsilon_{\mathrm{GHP}}$ within the range $[0.2 ; 2]$. The fact that the range of variation is slightly larger than a factor of two results from the difference in computation methods. The $\epsilon_{\mathrm{K} 06}$ computation using $320 \mathrm{~m}$ depth intervals provides a smoother estimate compared to the original $\epsilon_{\mathrm{GHP}}$. The $\epsilon_{\mathrm{K} 06}$ computation based on spectral variance computation over large depth intervals is especially relevant when a single profile is available by increasing the statistics. When repeated profiles are available at the same location, the use of $\epsilon_{\mathrm{GHP}}$ allows an $\epsilon$ estimate at higher vertical resolution. 


\section{LIST OF FIGURES}

Figure 1
Figure 2

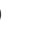

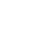

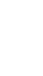

Figure 3 
Figure $4 \quad$ Vertical sections of internal tide current amplitude inferred from a 2D-linear generation model: for the Halmahera Sea $(a, c)$ and for the Ombai Strait (b, d). Panels (c, d) show the semi-diurnal M2 internal tide, panels $(a, b)$ the diurnal $K_{1}$ internal tide. The vertical section passes through stations $S_{1}, S_{2}$ and $S_{3}$, which are shown as dotted red lines in $(a, c)$ and similarly for station $S_{5}$ in $(b, d)$. White vertical lines denote the maximum extent of regions in which some baroclinic modes propagating against barotropic flows are trapped. . . . . . . . . . . . . . 46

Figure 5 Total meridional currents $\left(\mathrm{m} \mathrm{s}^{-1}, \mathrm{I}^{\text {st }}\right.$ column $)$ and baroclinic meridional currents minus the time averaged current $\left(\mathrm{m} \mathrm{s}^{-1}, 2^{\text {nd }}\right.$ column) from LADCP with isopycnals inferred from sorted density profiles superimposed with the following values: $[1022 ; 1025.5 ; 1026.25 ; 1026.75 ; 1026.9$ in (a)-(b), $[1022 ; 1025.5 ; 1026.5 ; 1026.90 ; 1026.97 ; 1026.99]$ in $(c)-(d)$, $[1022 ; 1025.5 ; 1026.5 ; 1026.90 ; 1026.95 ; 1027]$ in (e)-(f), $[1022 ; 1025.5 ; 1026.25 ; 1026.75 ; 102$ in $(\mathrm{g})-(\mathrm{h})$. Each line corresponds to a station: $S_{1}, S_{2}, S_{3}$ and $S_{5}$ respectively. The starting time of each LADCP profile appears as a vertical gray dashed line. . . . . . . . . . . . . . . 47 
Figure 6

Vertical section of the modulus of the horizontal current magnitudes in $\mathrm{m} \mathrm{s}^{-1}$ from SADCP data passing through the three stations of the Halmahera Sea (a). SADCP data were time averaged over two M2 tidal cycles at the location of the three stations in (a). Vertical sections of time series at stations $S_{1}, S_{2}$ and $S_{3}$ of the modulus of the horizontal current and of its vertical shear are shown in $(b)$ and $(c) \ldots \ldots \ldots \ldots \ldots \ldots$

Figure 7 Dissipation rate from velocity microstructure (color log-scale, units in $\left.\mathrm{W} \mathrm{kg}^{-1}\right)$, vertical shear of horizontal velocities from ship-ADCP ( magenta colorscale, from o to $0.03 \mathrm{~s}^{-1}$, gray when no data) and isopycnals inferred from sorted density profiles (same black contours as in Figure5) as a function of time for the stations $S_{1}-S_{3}$ in the Halmahera Sea and $S_{5}$ in the Ombai Strait. Black vertical dotted lines denote the time location of the CTD casts. Note that the maximum depth of each subplot corresponds to the maximum station depth. . . . . . . . . . . . . . . . . 49 
Figure 8

Time-mean profiles of energy dissipation rate $\epsilon,(a)$, vertical diffusion coefficient $K_{z}$, (b), vertical diffusion coefficient based on Osborn method $\mathrm{K} z_{\text {Osborn }}$ (c), and buoyancy frequency square $\mathrm{N}^{2}$, (d), for the 5 stations. Note that a 10-meter moving average has been applied for better vizualisation. Maximum values and standard deviations are listed in Tables 2 and 3. The bottom depth of the stations is indicated in (d) by an horizontal colored line except for station $S_{4}$ whose bottom depth is $4750 \mathrm{~m} . \ldots . . . . . .50$

Figure 9 Time-averaged profiles of turbulence intensity (blue) for stations $S_{1}, S_{2}, S_{3}$, and $S_{5}$ and percentage of occurrence of $\mathrm{I}<1000$ (red). The turbulence intensity profile for the single profile of station $S_{4}$ plotted is shown. All curves have been smoothed using a 10-m moving average for clarity. ................ 51

Figure 10 Mean profiles of total baroclinic tidal energy for the 4 stations (diurnal+semi-diurnal). The bottom depth of the stations is indicated by an horizontal colored line. . . . . . . . . . . . 52

Figure $11 \quad$ Mean profiles of $\epsilon$ derived from finescale parameterizations and from VMP measurements are compared at each station. The bottom depth of the stations is indicated by a black horizontal line except for station $s_{4} \ldots \ldots \ldots \ldots \ldots$ 
Figure 12

.

Figure 13

Figure 14

Figure 15 
Figure 16 Mean profiles of $\epsilon$ derived from the Kunze et al. (2006) finescale parameterization at all stations, $\epsilon_{\mathrm{K} 06}$ is shown in blue, and $<$ $\epsilon_{V M P}>$ averaged over the $320 \mathrm{~m}$ computation intervals with an overlap of $160 \mathrm{~m}$ in red. $<\epsilon_{\mathrm{GHP}}>$ is shown as well for comparison. The bottom depth of the stations is indicated by a black horizontal line except for station $S_{4} \ldots \ldots \ldots \ldots \ldots$

\section{LIST OF TABLES}

Table $1 \quad$ Position of the stations, depths and number of VMP profiles, maximum and mean of barotropic velocity modulus. . . . . . . . . 59

Table 2 Mean, standard deviation and extrema of $\epsilon_{\mathrm{VMP}}\left(\mathrm{W} \mathrm{kg}^{-1}\right)$ and of $K_{z}\left(m^{2} s^{-1}\right)$. The average and standard deviation, $\sigma$, were first computed over time and next averaged over depth. The average of $\mathrm{K} z_{\mathrm{Osborn}}$ is displayed for comparison. . . . . . . . 60

Table $3 \quad$ Same as Table 2 but within the thermocline. The depth range for thermocline statistics is $[50-200] \mathrm{m}$ except at station $S_{4}$ with a $[50-120] m$ depth range. . . . . . . . . . . . . 61

Table $4 \quad$ Percentage of agreement within a factor of 10 (1st column), 5 (2nd column) and 2 (3rd column) of $\epsilon_{\mathrm{IR}}$ for data such that $\mathrm{L}_{\mathrm{O}}>8 \mathrm{~m} . \quad$. 62 
${ }_{806} 7$ FIGURES 


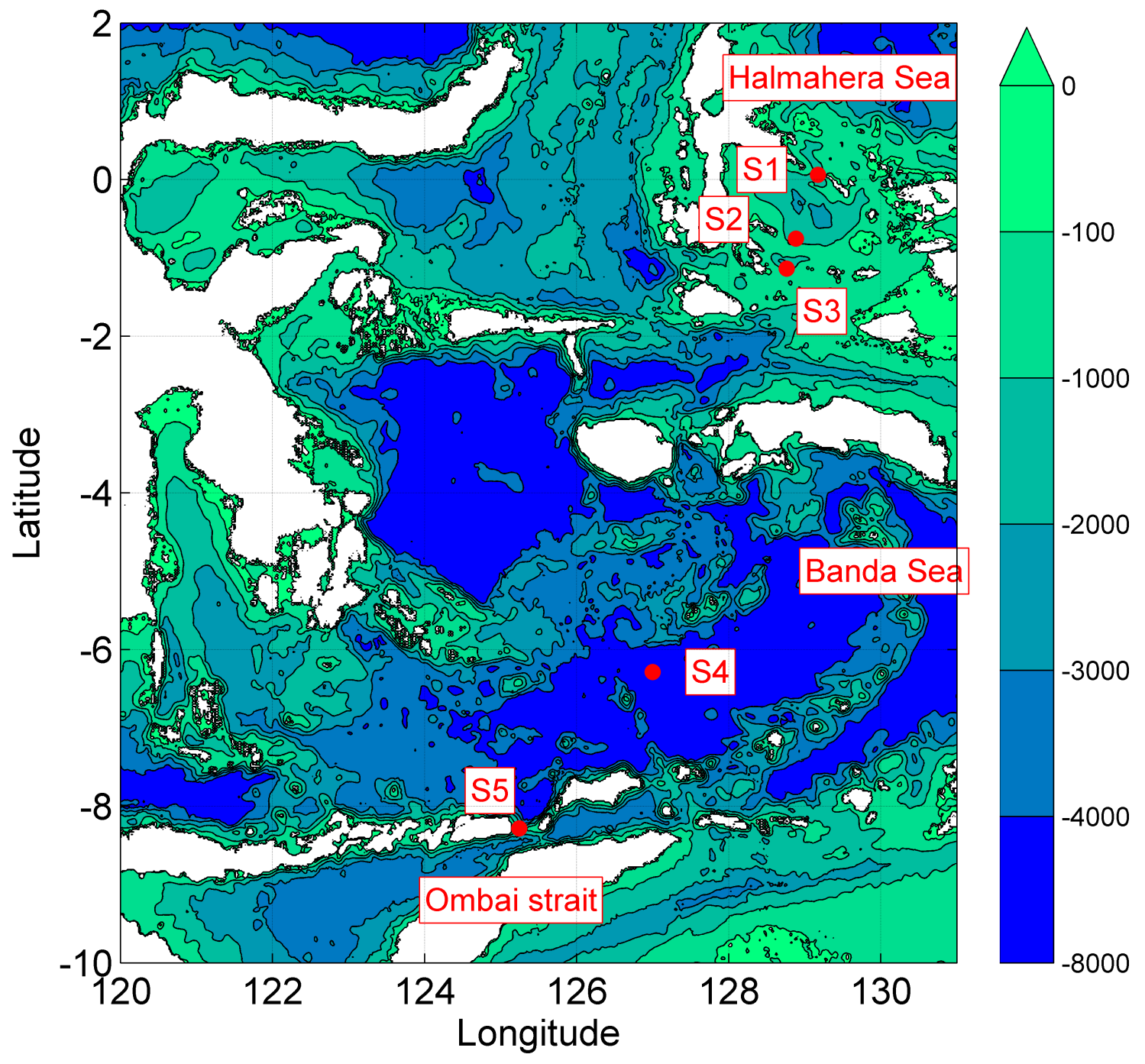

Figure 1: Bathymetry of the Indonesian seas (Smith and Sandwell, http : //topex.ucsd.edu/marine_topo/). The three main areas of interest are labelled and stations are indicated by red circles. 
(a) Generating force $\mathrm{K} 1$

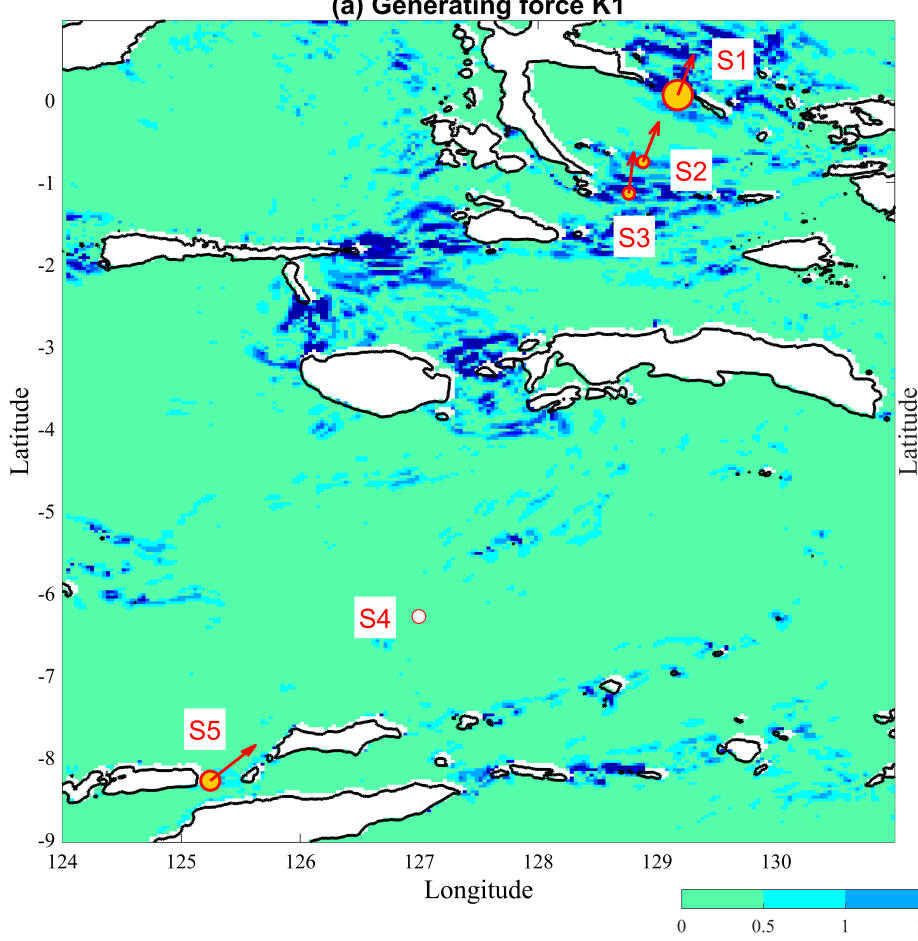

(b) Generating force M2

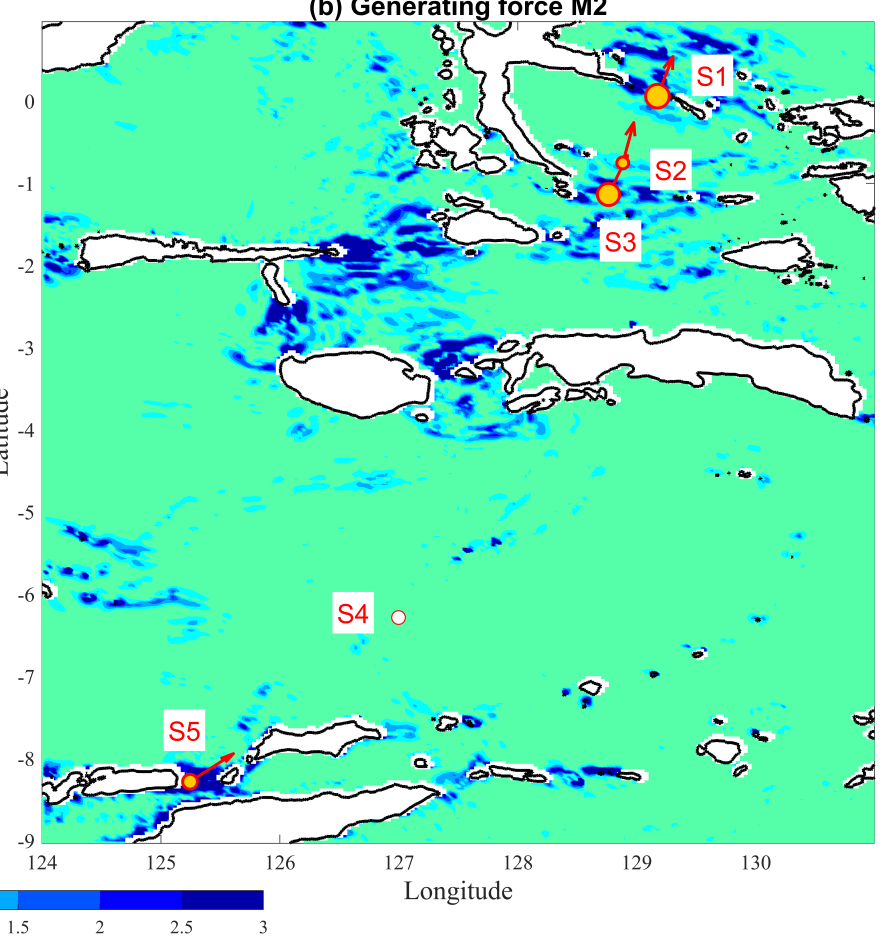

Figure 2: Baroclinic tide generating force inferred from the TPXO 7.2 model for (a) diurnal $\mathrm{K}_{1}$ and (b) semi-diurnal M2 baroclinic tides $\left(10^{-4} \mathrm{~m} \mathrm{~s}^{-2}\right)$; stations are indicated by red circles, except for the single profile station $S_{4}$ with a white disk added; the direction of the barotropic tidal flux for each constituent is shown in red and its modulus is proportional to the radius of the outer red circle of the yellow disks centered at the station location with reference circle taken at station $S_{2}$, where the barotropic tidal flux is of $110 \mathrm{~m}^{2} \mathrm{~s}^{-1}$ for the diurnal frequency and of $140 \mathrm{~m}^{2} \mathrm{~s}^{-1}$ for the semi-diurnal frequency. 

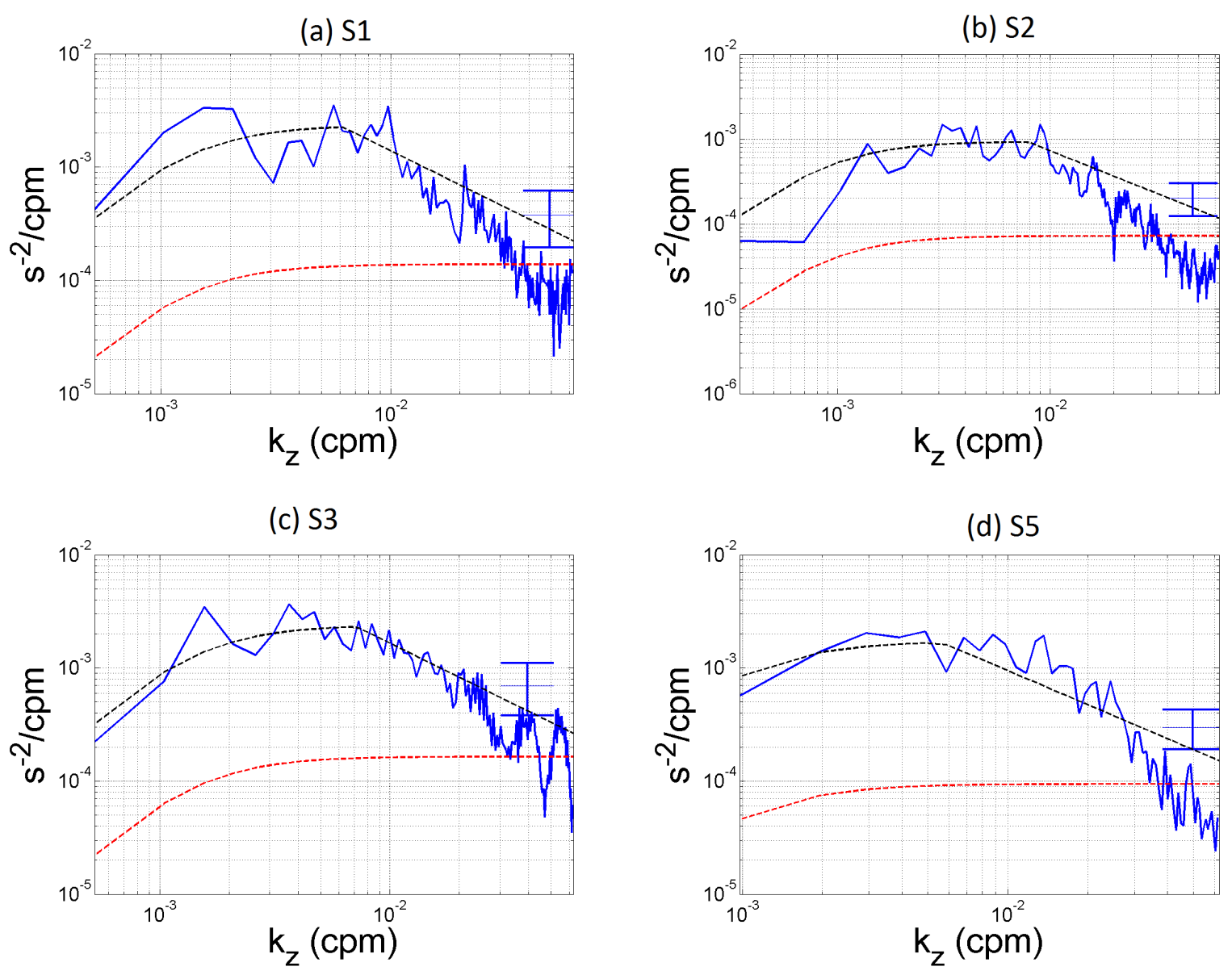

(e) S4

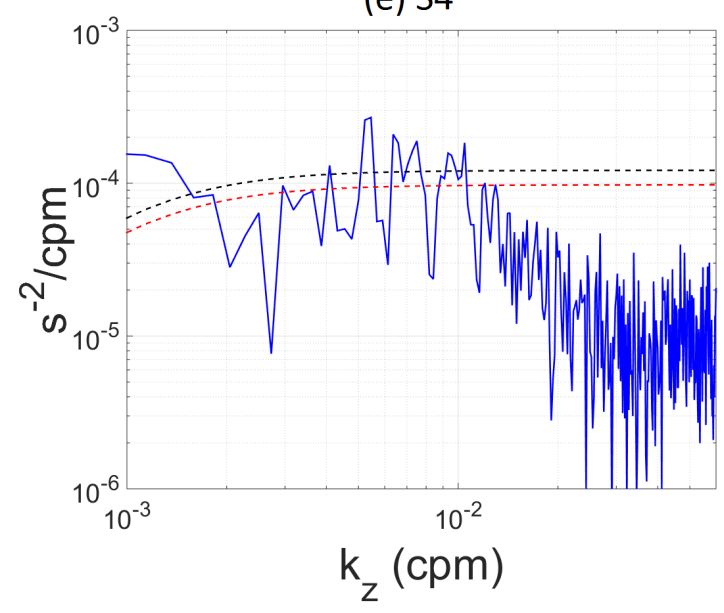

Figure 3: Observed shear spectra from LADCP (blue), canonical GM spectra (red) and GM spectra fitted to the observed shear variance (black). Ratios between observed and canonical GM shear variances computed up to $k_{c}=1 / 100 \mathrm{cpm}$ are equal to: $17,13,15,18$ and 1.2 for stations $S_{1}, S_{2}, S_{3}, S_{5}$ and $S_{4}$. The $95 \%$ confidence interval is shown with an error bar. 

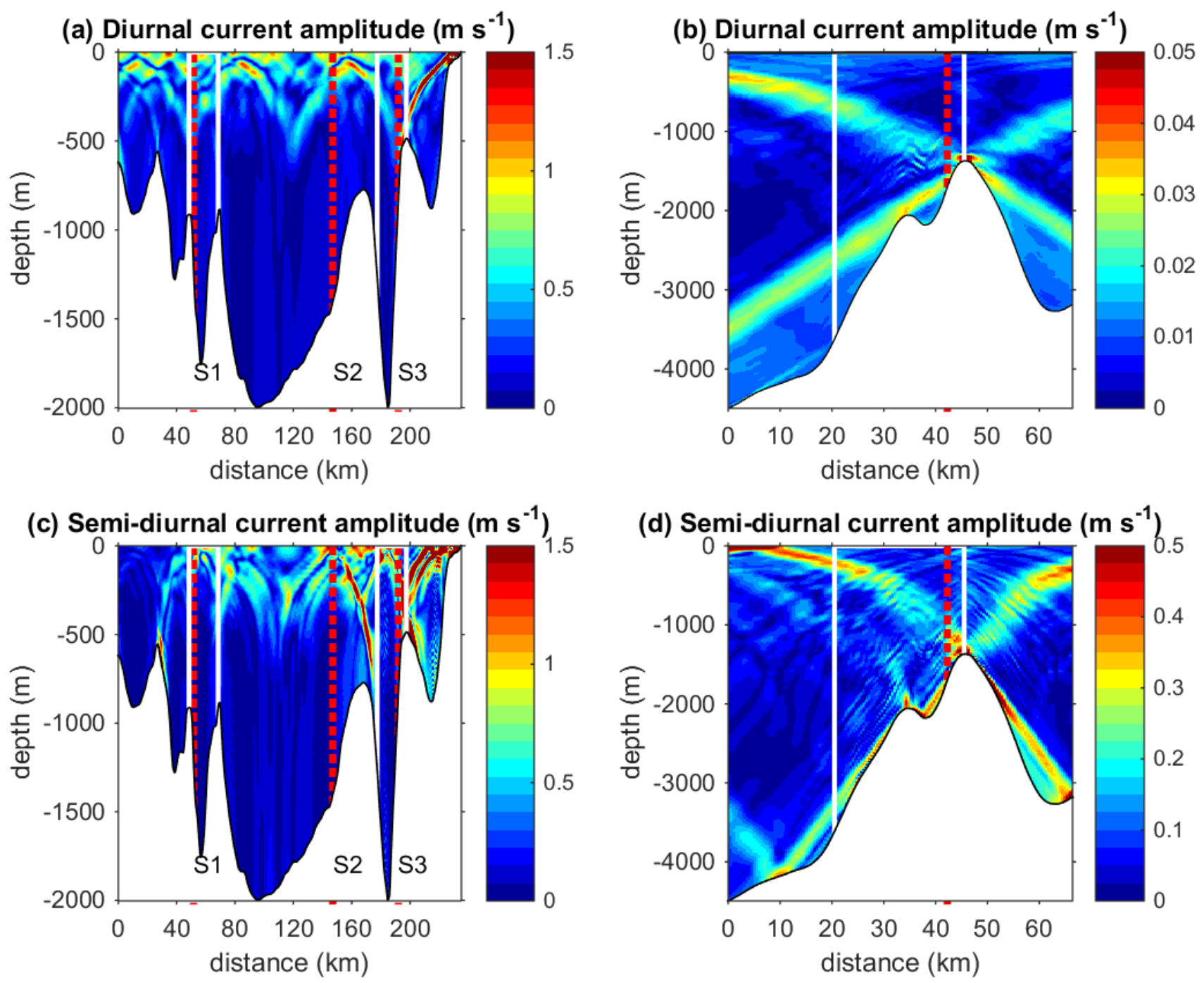

Figure 4: Vertical sections of internal tide current amplitude inferred from a 2D-linear generation model: for the Halmahera Sea $(a, c)$ and for the Ombai Strait $(b, d)$. Panels $(c, d)$ show the semi-diurnal M2 internal tide, panels $(\mathrm{a}, \mathrm{b})$ the diurnal $\mathrm{K}_{1}$ internal tide. The vertical section passes through stations $S_{1}, S_{2}$ and $S_{3}$, which are shown as dotted red lines in $(a, c)$ and similarly for station $S_{5}$ in $(b, d)$. White vertical lines denote the maximum extent of regions in which some baroclinic modes propagating against barotropic flows are trapped. 
(a). S1- $v_{y}$

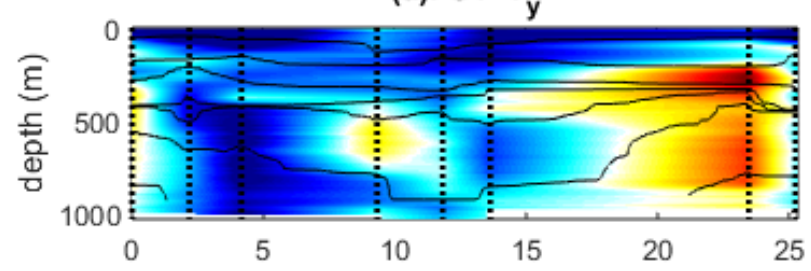

(c). S2- v

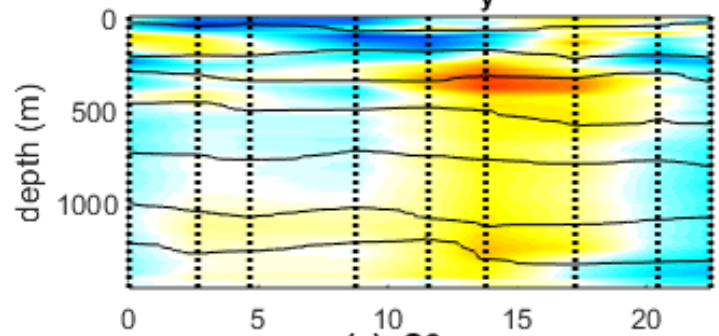

(e). S3- v

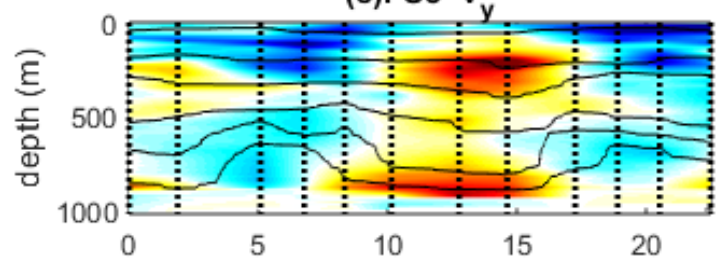

(g). S5- v $y$

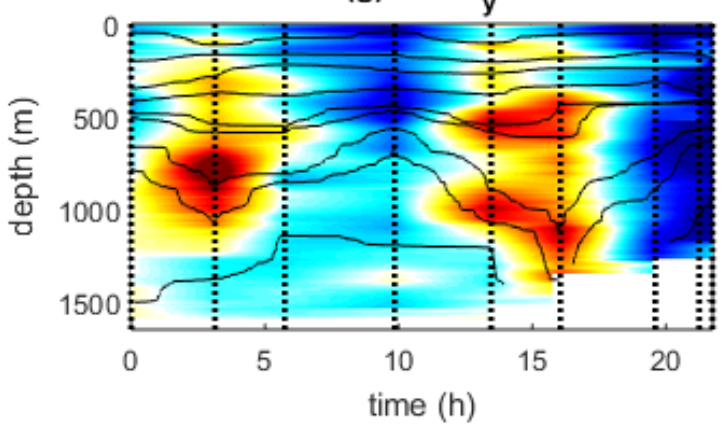

(b). S1- $v_{y}$ perturbation

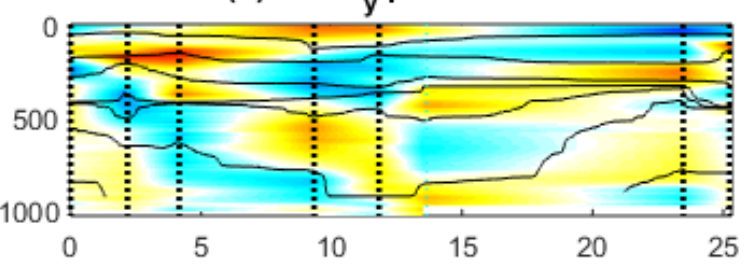

d). S2- $v_{y}$ perturbation

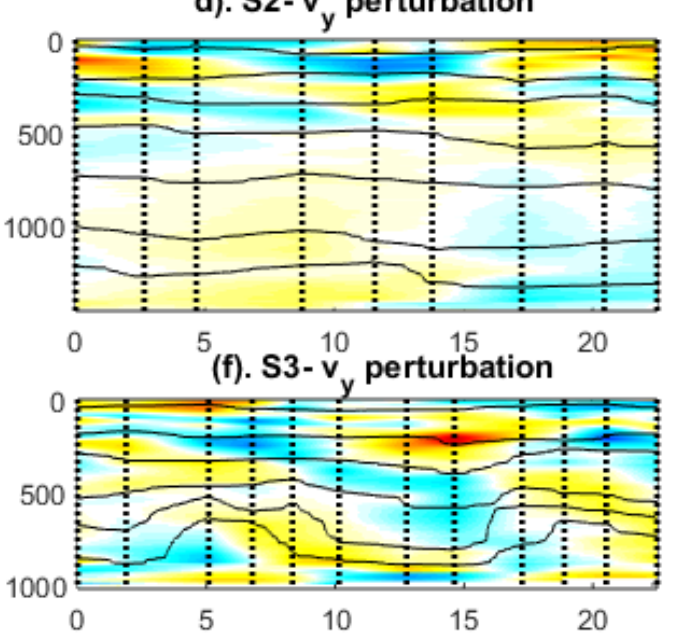

(h). S5- $v_{y}$ perturbation

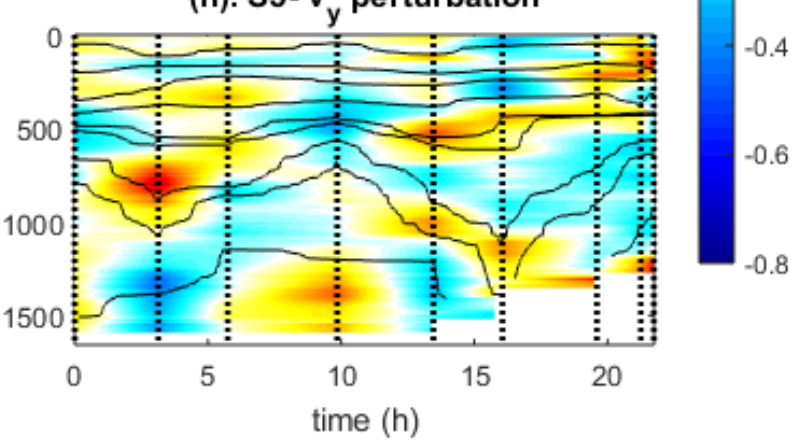

Figure 5: Total meridional currents $\left(\mathrm{m} \mathrm{s}^{-1}, 1^{\text {st }}\right.$ column) and baroclinic meridional currents minus the time averaged current $\left(\mathrm{m} \mathrm{s}^{-1}, 2^{\text {nd }}\right.$ column) from LADCP with isopycnals inferred from sorted density profiles superimposed with the following values: $[1022 ; 1025.5 ; 1026.25 ; 1026.75 ; 1026.95 ; 1027]$ in $(a)-(b)$, $[1022 ; 1025.5 ; 1026.5 ; 1026.90 ; 1026.97 ; 1026.99]$ in (c)-(d), $[1022 ; 1025.5 ; 1026.5 ; 1026.90 ; 1026.95 ; 1027]$ in (e)-(f), $[1022 ; 1025.5 ; 1026.25 ; 1026.75 ; 1026.95 ; 1027.2 ; 1027.4]$ in $(\mathrm{g})-(\mathrm{h})$. Each line corresponds to a station: $S_{1}, S_{2}, S_{3}$ and $S_{5}$ respectively. The starting time of each LADCP profile appears as a vertical gray dashed line. 


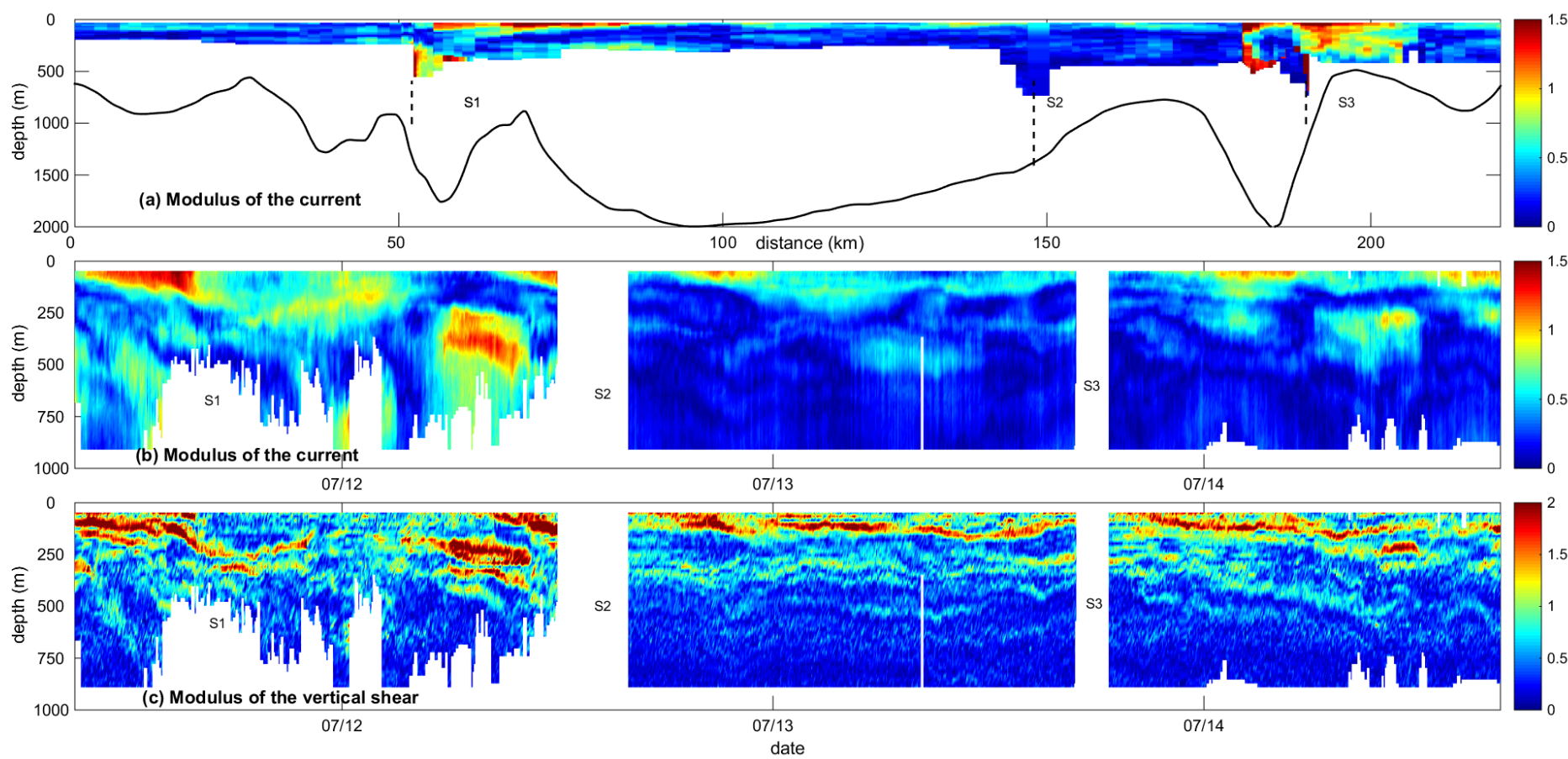

Figure 6: Vertical section of the modulus of the horizontal current magnitudes in $\mathrm{m} \mathrm{s}^{-1}$ from SADCP data passing through the three stations of the Halmahera Sea (a). SADCP data were time averaged over two M2 tidal cycles at the location of the three stations in (a). Vertical sections of time series at stations $S_{1}, S_{2}$ and $S_{3}$ of the modulus of the horizontal current and of its vertical shear are shown in (b) and (c). 
(a) S1
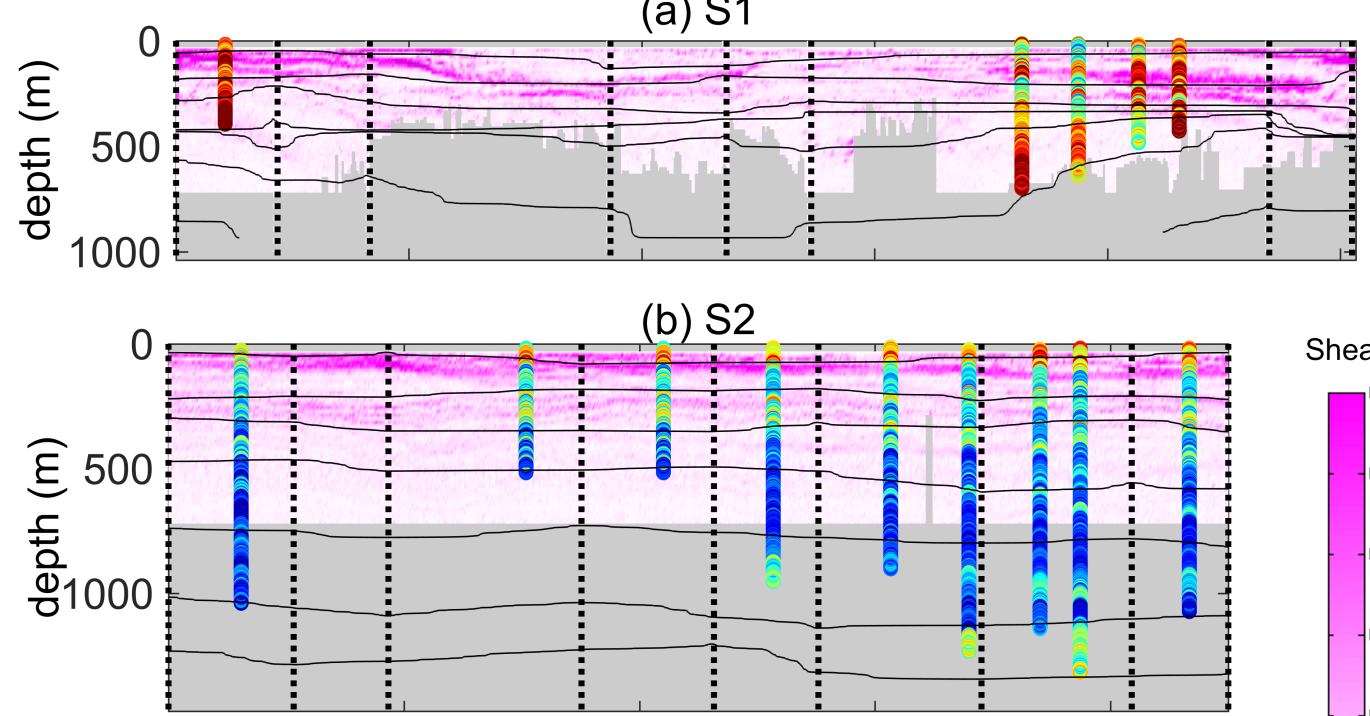

(c) $\mathrm{S3}$

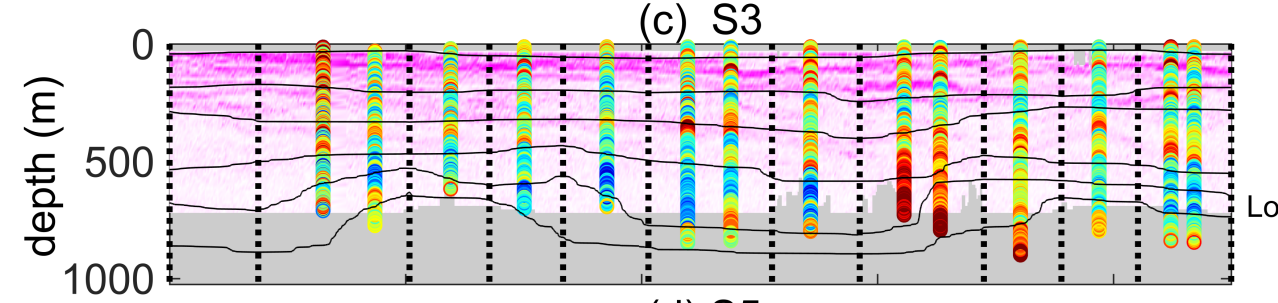

(d) S5
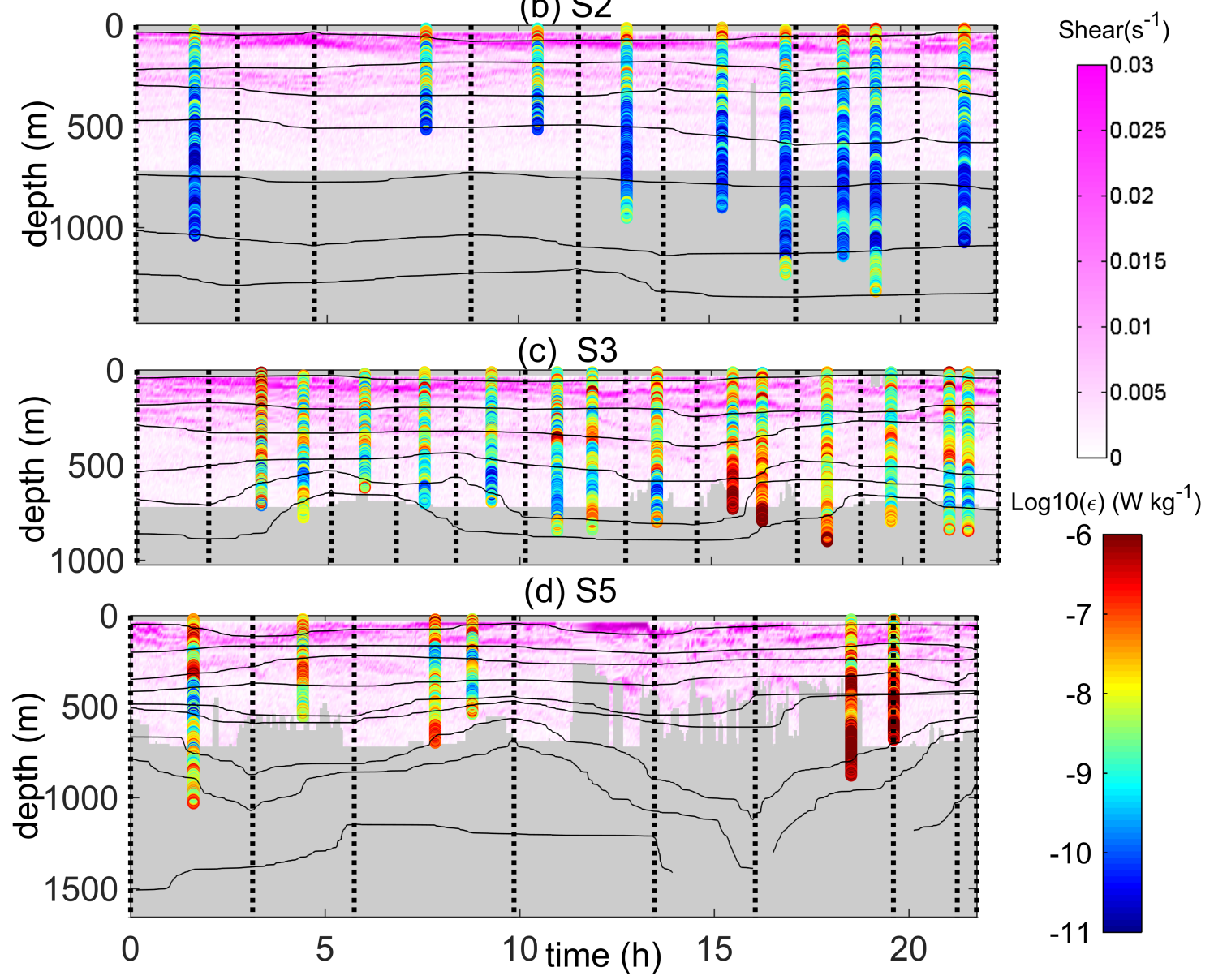

Figure 7: Dissipation rate from velocity microstructure (color log-scale, units in $\mathrm{W} \mathrm{kg}^{-1}$ ), vertical shear of horizontal velocities from ship-ADCP ( magenta colorscale, from o to $0.03 \mathrm{~s}^{-1}$, gray when no data) and isopycnals inferred from sorted density profiles (same black contours as in Figure5) as a function of time for the stations $S_{1}-S_{3}$ in the Halmahera Sea and $S_{5}$ in the Ombai Strait. Black vertical dotted lines denote the time location of the CTD casts. Note that the maximum depth of each subplot corresponds to the maximum station depth. 

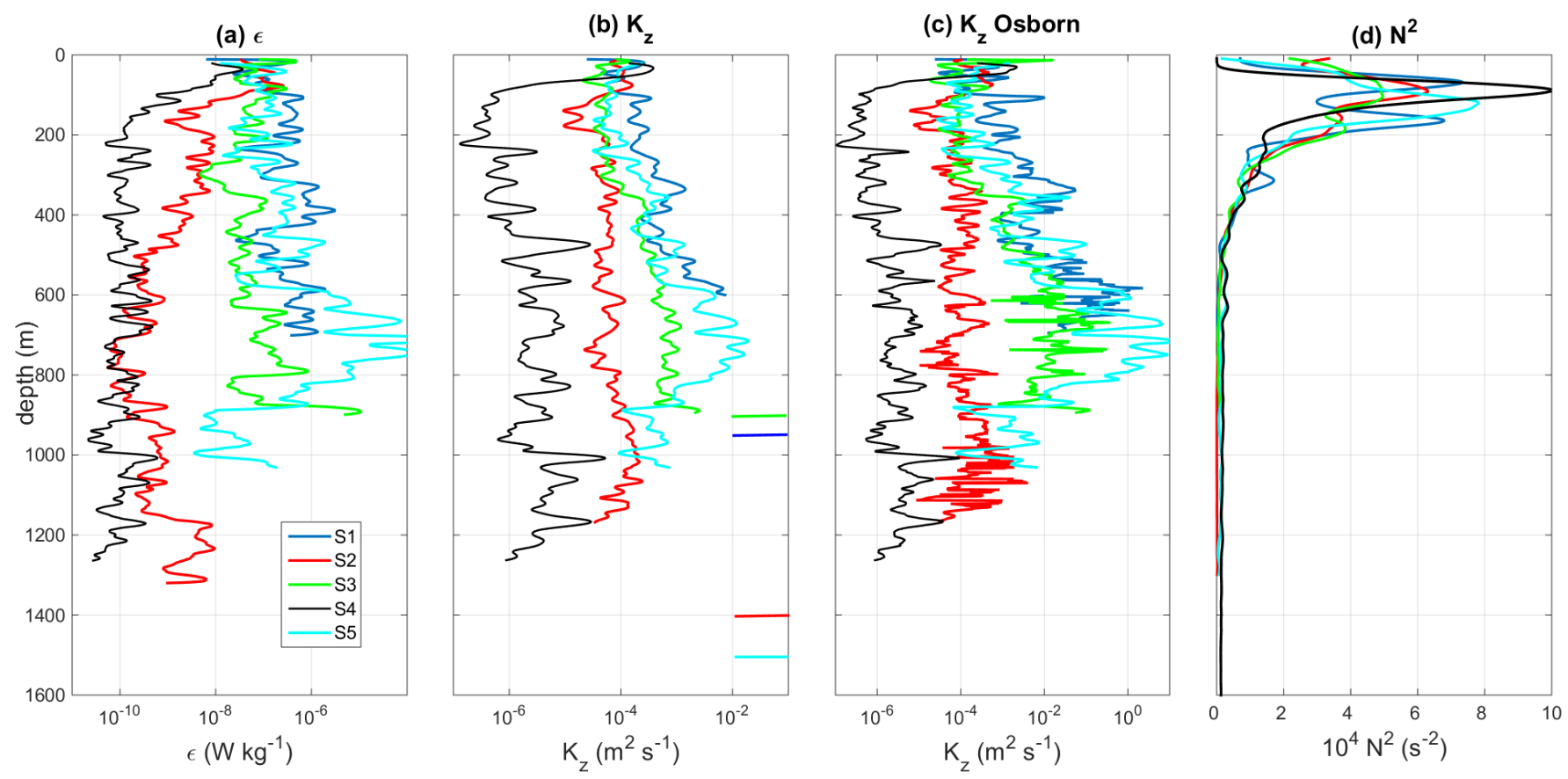

Figure 8: Time-mean profiles of energy dissipation rate $\epsilon,(a)$, vertical diffusion coefficient $K_{z}$, (b), vertical diffusion coefficient based on Osborn method $\mathrm{K} z_{\mathrm{Osborn}},(\mathrm{c})$, and buoyancy frequency square $\mathrm{N}^{2},(\mathrm{~d})$, for the 5 stations. Note that a 10-meter moving average has been applied for better vizualisation. Maximum values and standard deviations are listed in Tables 2 and 3. The bottom depth of the stations is indicated in (d) by an horizontal colored line except for station $S_{4}$ whose bottom depth is $4750 \mathrm{~m}$. 

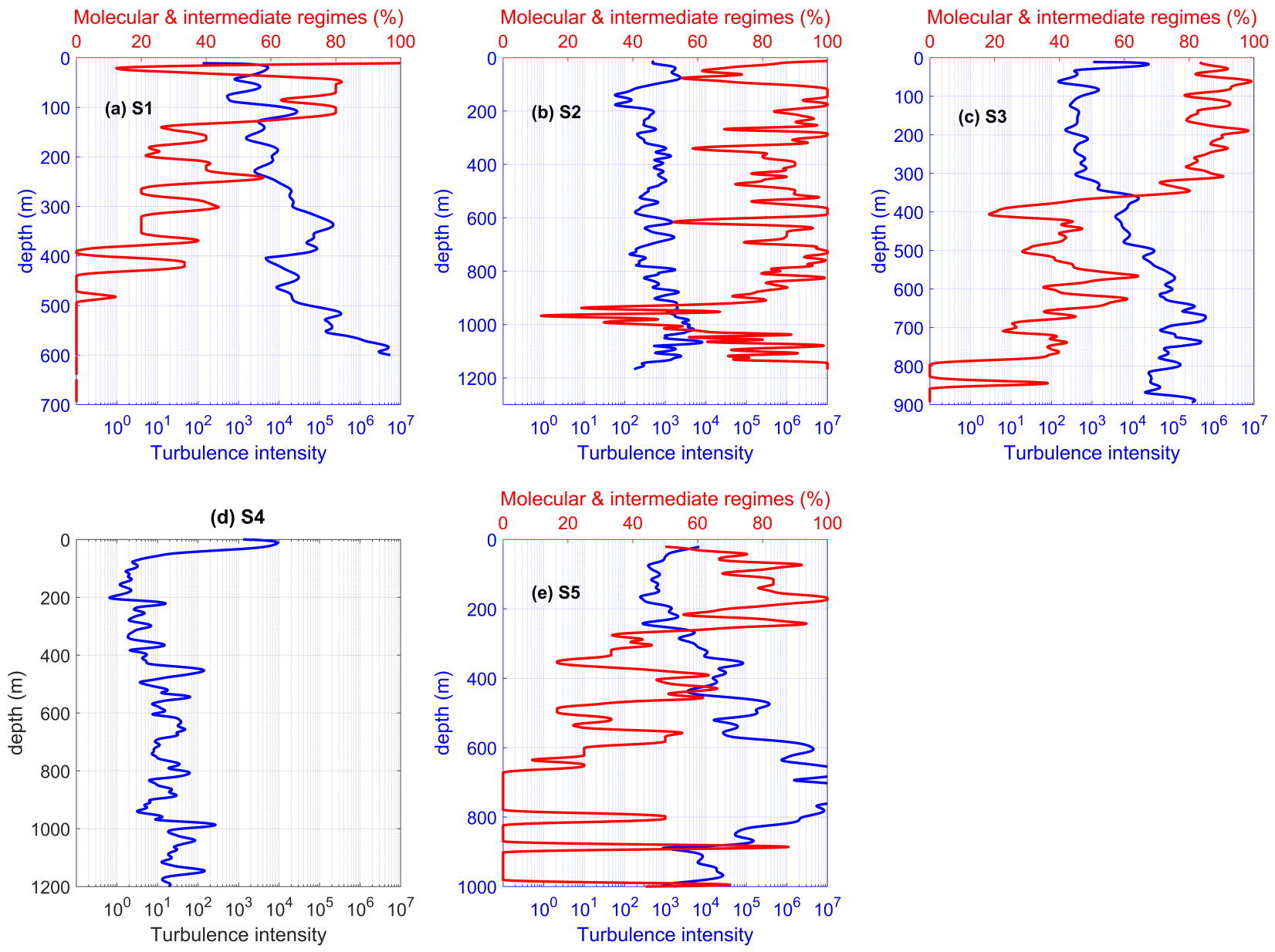

Figure 9: Time-averaged profiles of turbulence intensity (blue) for stations $S_{1}, S_{2}, S_{3}$, and $S_{5}$ and percentage of occurrence of I $<1000$ (red). The turbulence intensity profile for the single profile of station $\mathrm{S}_{4}$ plotted is shown. All curves have been smoothed using a 10-m moving average for clarity. 


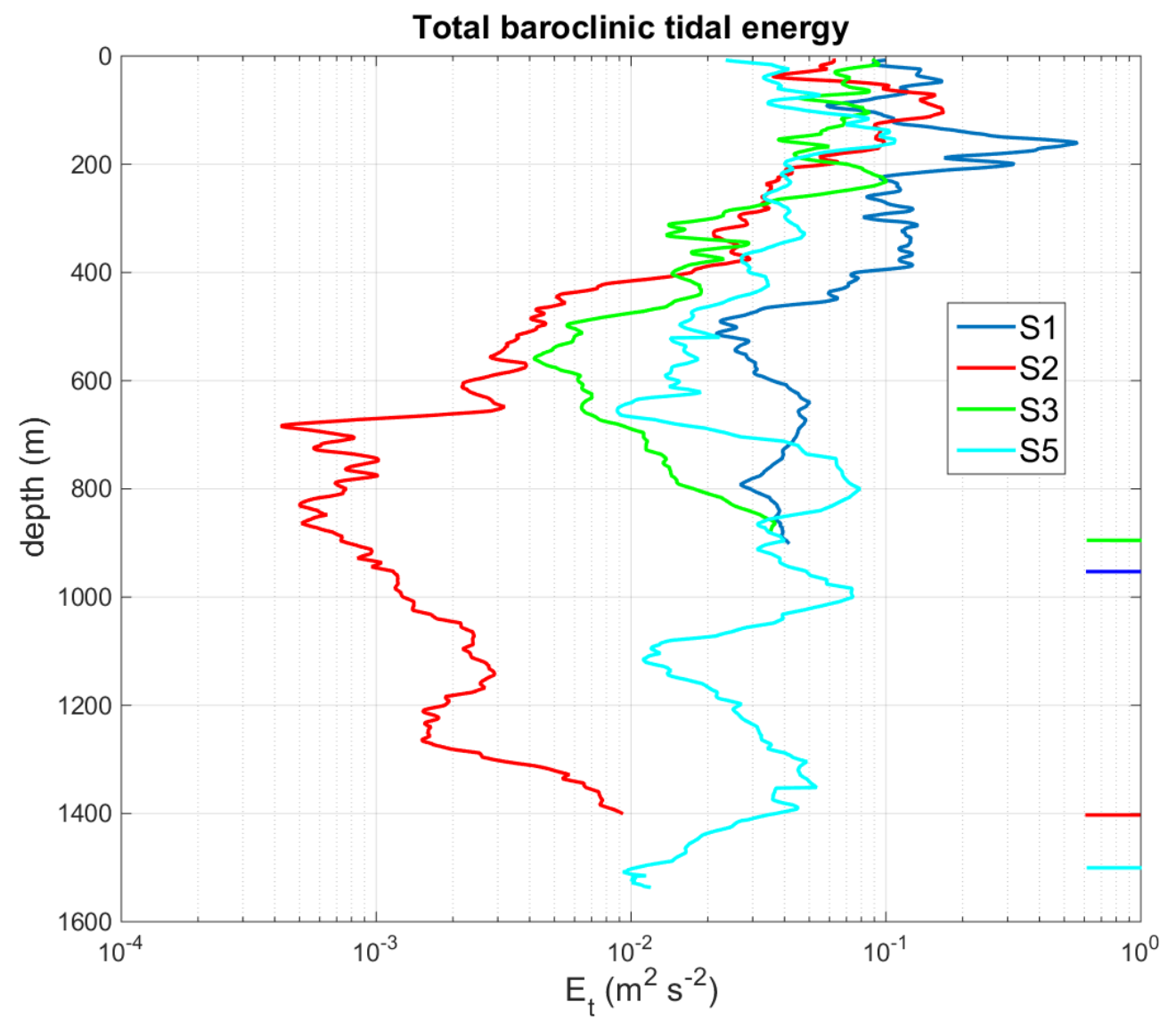

Figure 10: Mean profiles of total baroclinic tidal energy for the 4 stations (diurnal+semi-diurnal). The bottom depth of the stations is indicated by an horizontal colored line. 
(a) $\mathrm{S1}$

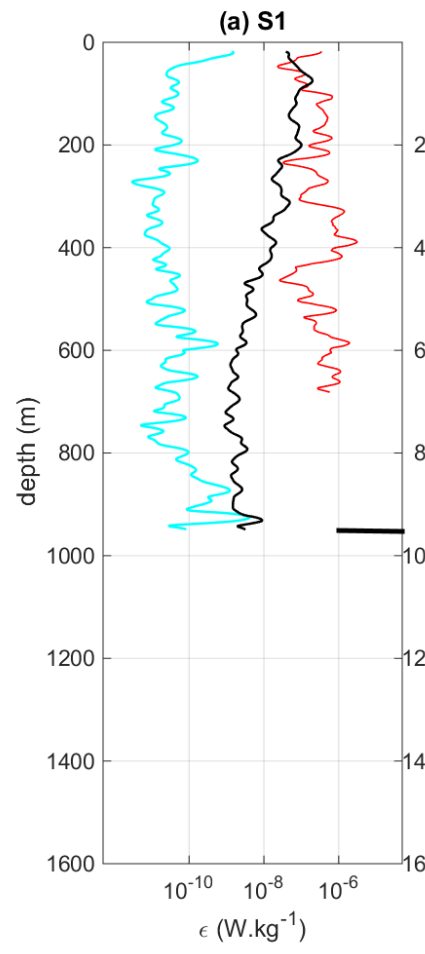

(b) $\mathrm{S} 2$

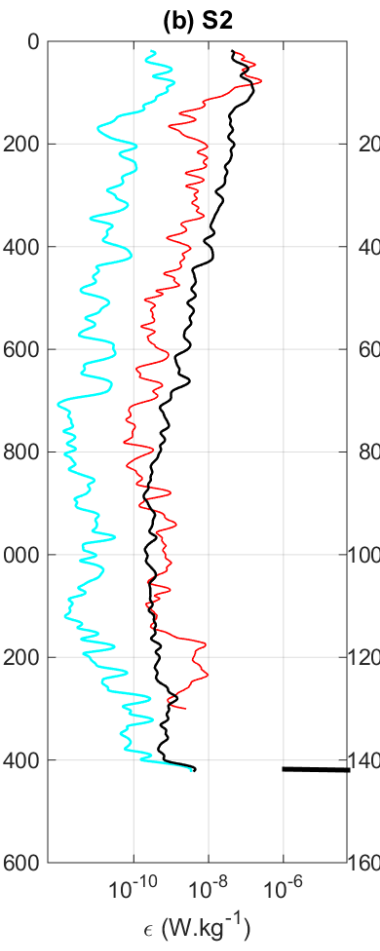

(c) $\mathrm{S3}$

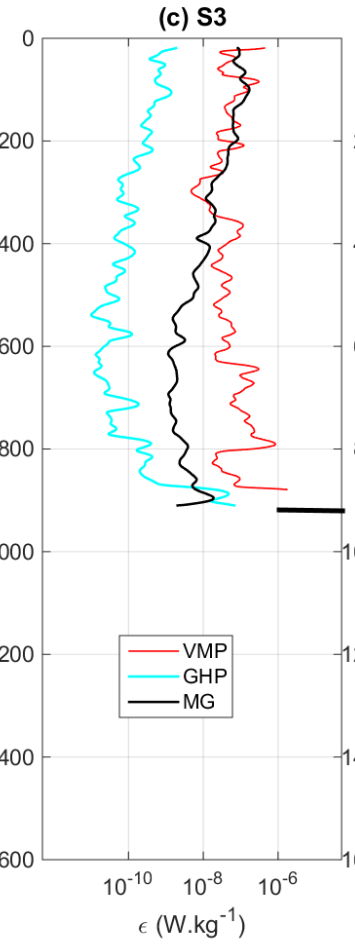

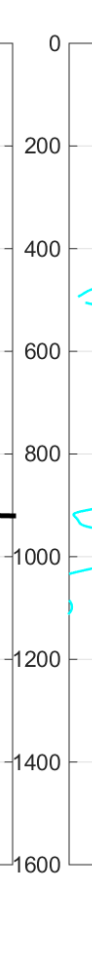

(d) 54
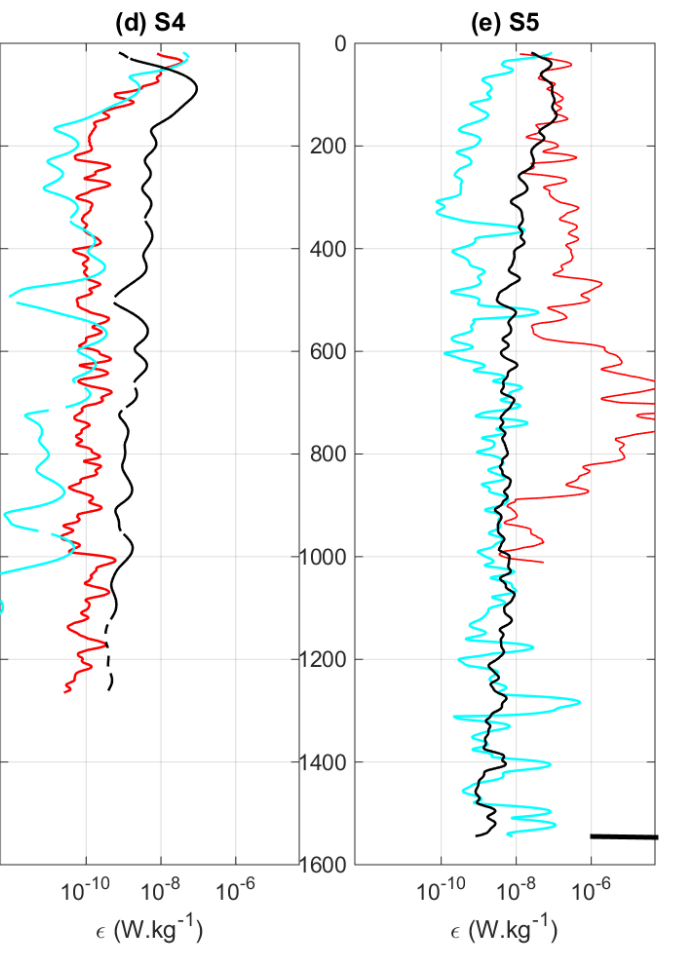

Figure 11: Mean profiles of $\epsilon$ derived from finescale parameterizations and from VMP measurements are compared at each station. The bottom depth of the stations is indicated by a black horizontal line except for station $S_{4}$. 

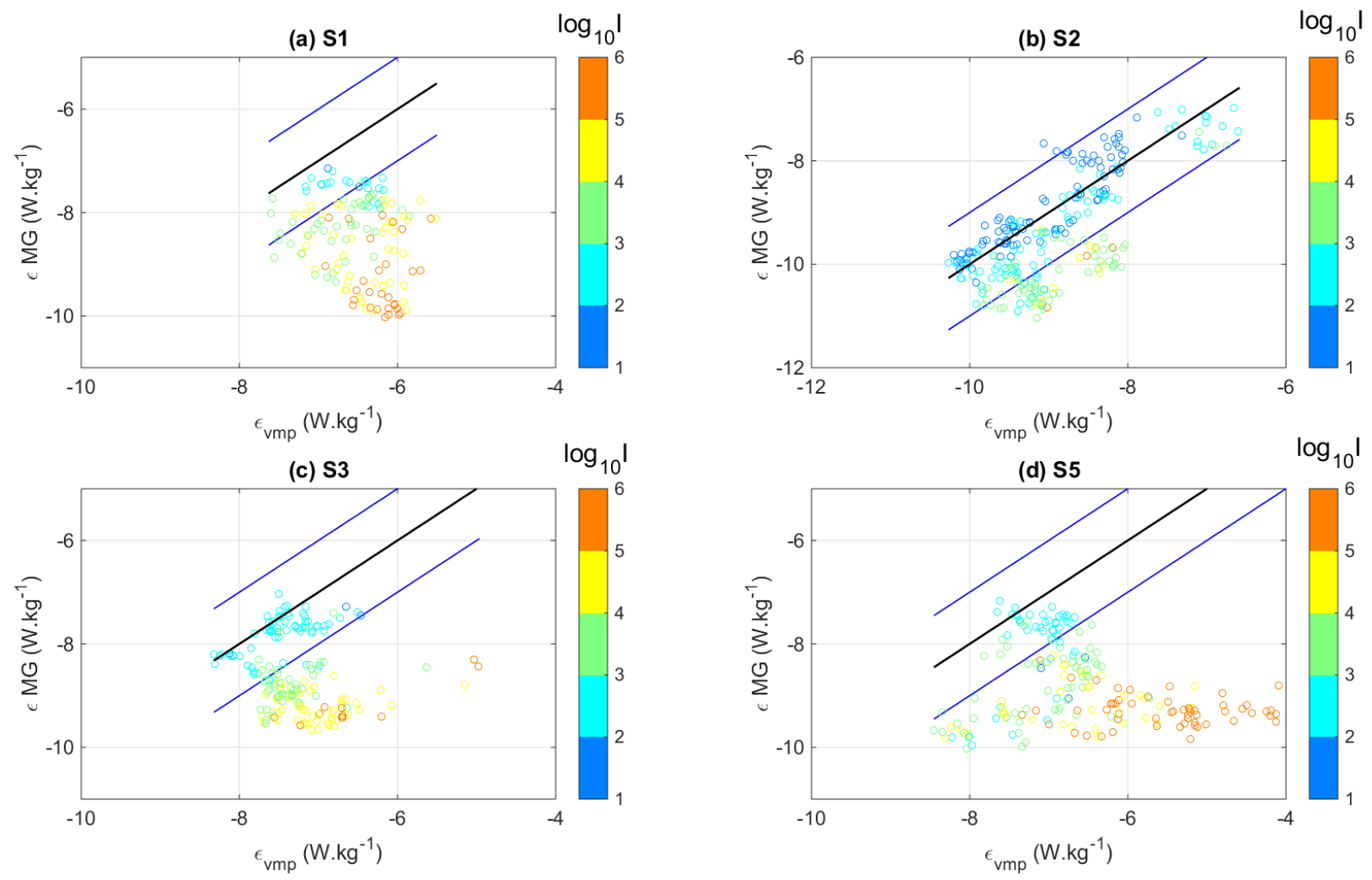

Figure 12: Mean profiles of $\epsilon$ derived from MG finescale parameterization, $\epsilon_{M G}$, for stations $S_{1}$, $S_{2}, S_{3}$ and $S_{5}$, as a function of $\epsilon_{V M P}$ with turbulence intensity displayed in color. Black lines (resp. blue) denote a perfect agreement (resp. a factor of 10) between blue $\epsilon_{\mathrm{MG}}$ and $\epsilon_{\mathrm{VMP}}$ 
(a) S2- $\epsilon_{\mathrm{VMP}} \quad \log 10\left(\epsilon\left(\mathrm{W} \mathrm{kg}^{-1}\right)\right)$

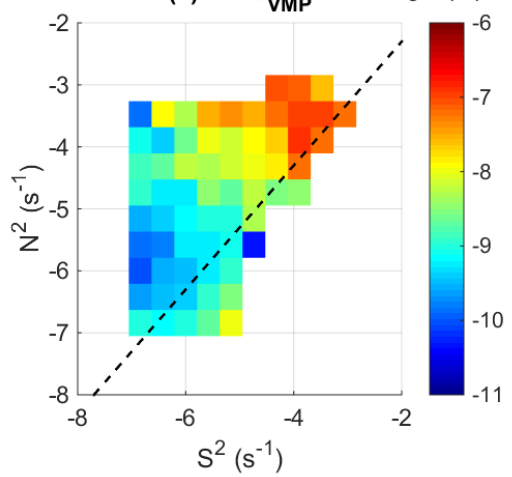

(d) S2- $\epsilon_{\text {MG }}$

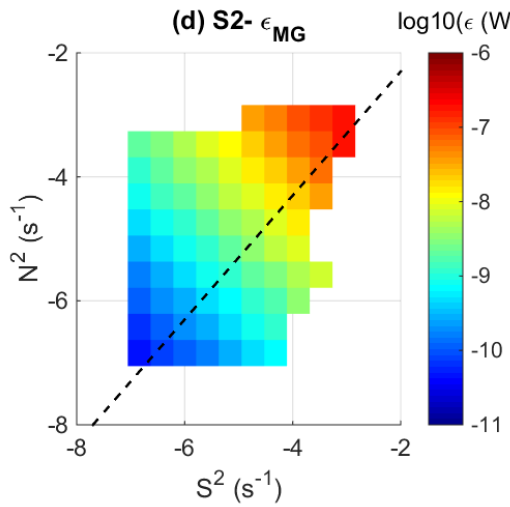

(b) S3- $\epsilon_{\text {VMP }}$

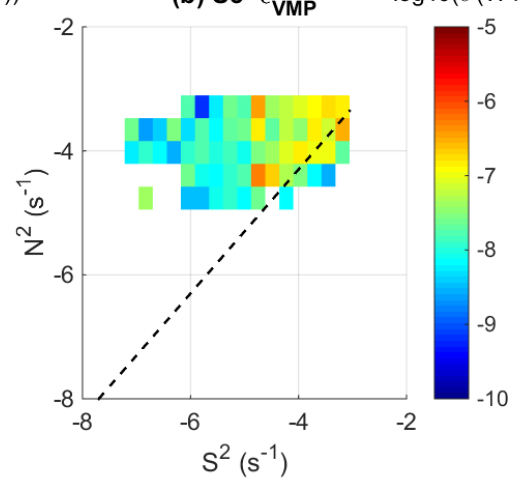

(e) S3- $\epsilon_{\text {MG }}$

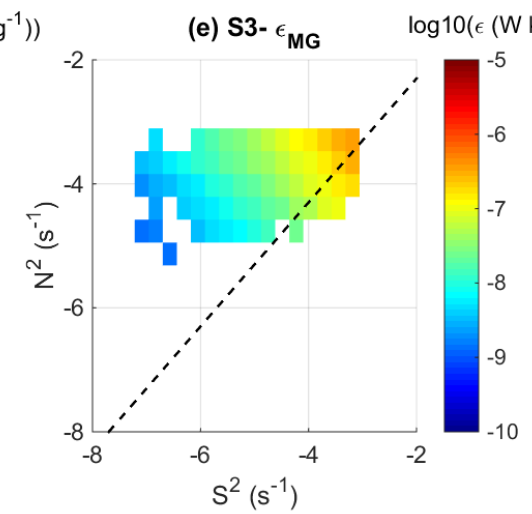

(c) S4- $\epsilon_{\mathrm{VMP}} \quad \log 10\left(\epsilon\left(\mathrm{W} \mathrm{kg}^{-1}\right)\right)$

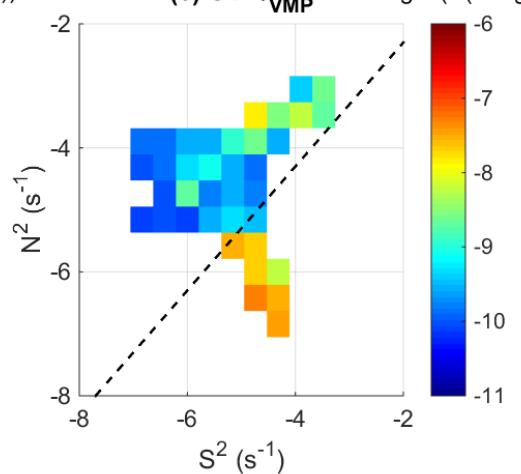

(f) $S 4-\epsilon_{\mathrm{GHP}}$

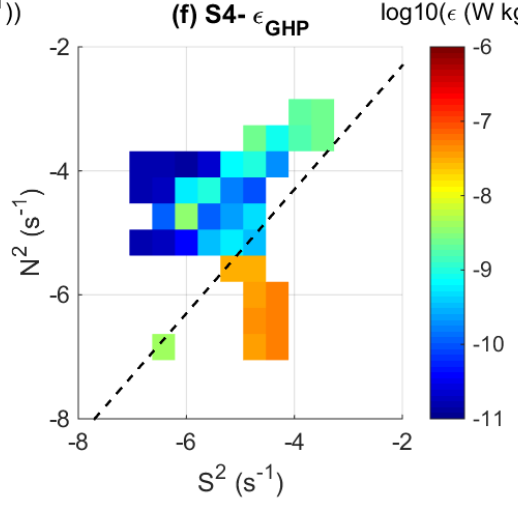

Figure 13: Bin-averaged dissipation rate (first raw: $\epsilon_{V M P}$; second raw: parameterization) as a function of shear and stratification: station $S_{2}$ (a) and (d), upper $300 \mathrm{~m}$ of station $S_{3}$ (b) and (e), station $S_{4}(\mathrm{c})$ and (f). Critical Richardson number, $R i=0.25$, is shown as a black dashed line. Note all CTD and LADCP profiles were included for the parameterized $\epsilon$ and not only those performed when VMP profiles were available. 
(a) $\mathbf{S 1}$

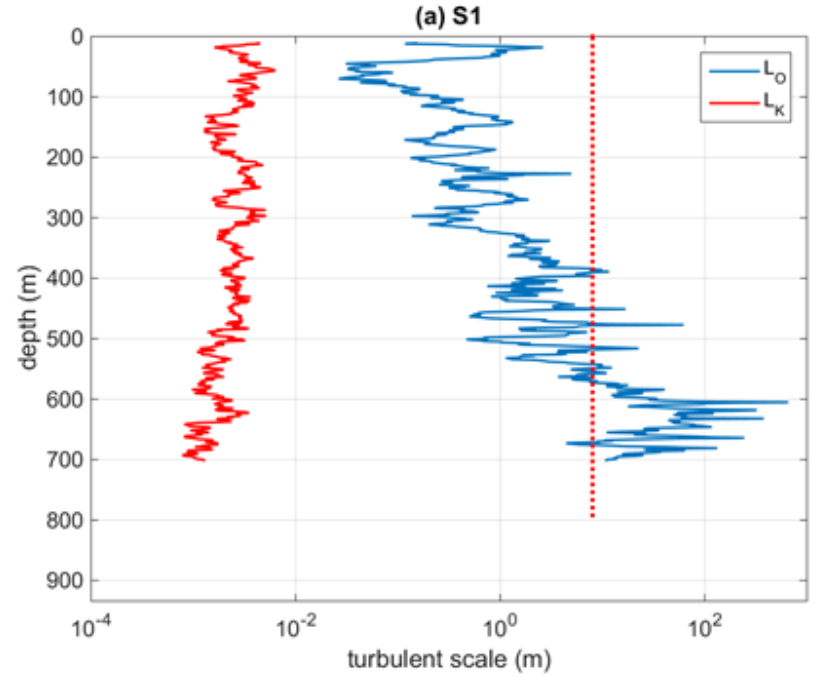

(c) S3

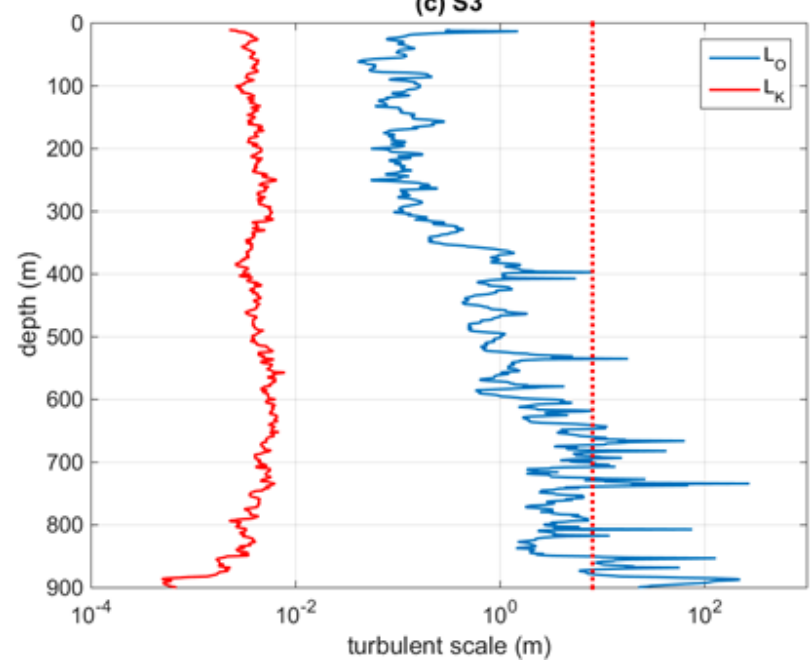

(b) S2

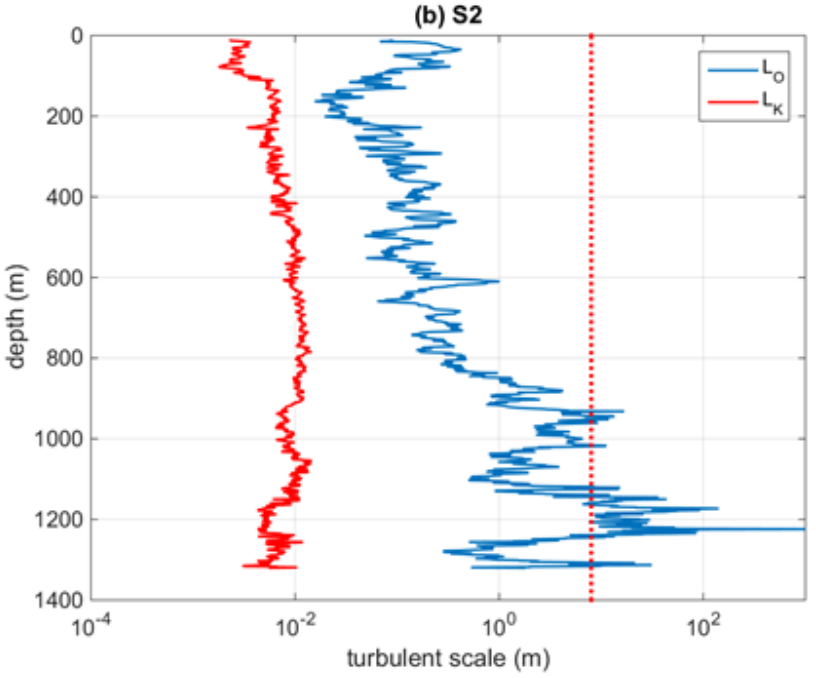

(d) S5

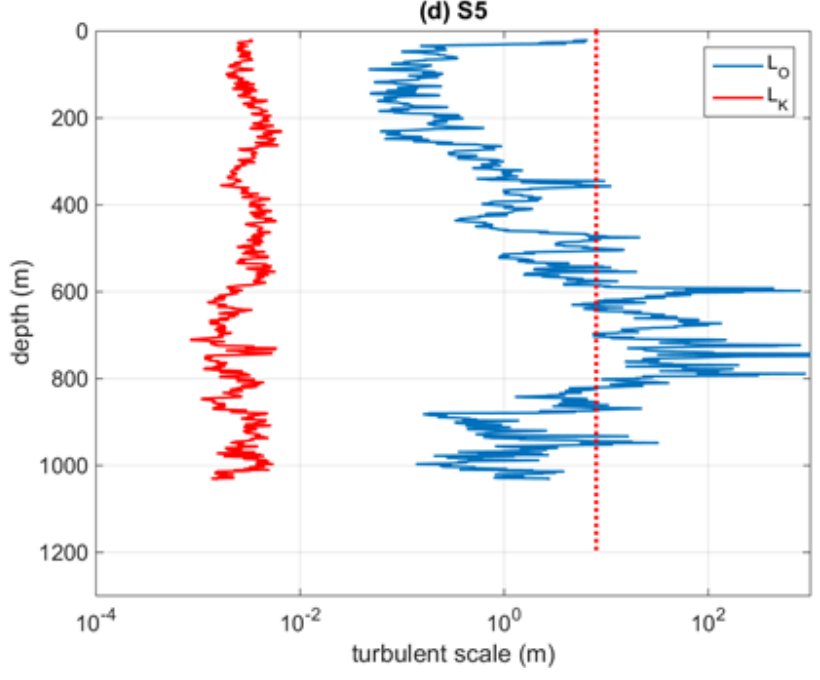

Figure 14: Mean profiles of Ozmidov and Kolmogorov scales as a function of depth for station $S_{1}(a)$, station $S_{2}\left(\right.$ b), station $S_{3}\left(\right.$ c) and station $S_{5}($ d). The red dotted line denotes the vertical LADCP bin size ( $8 \mathrm{~m})$. 
(a) S1

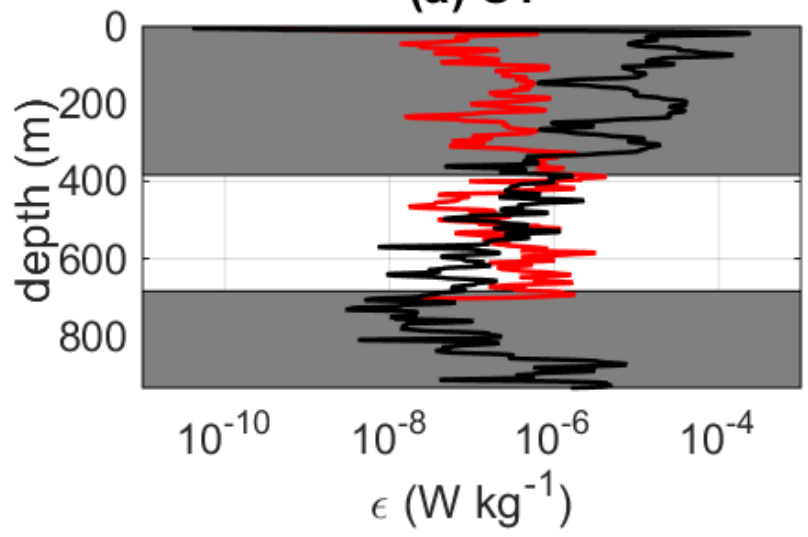

(c) S3

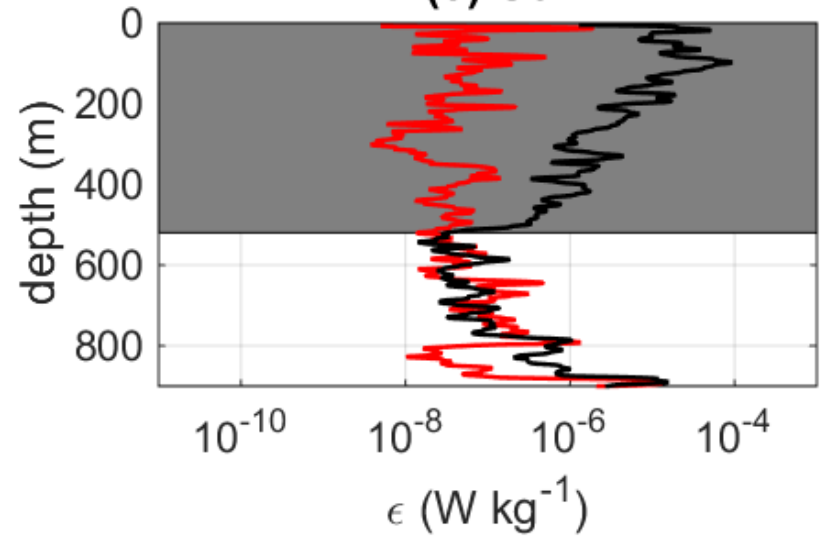

(b) $\mathrm{S2}$

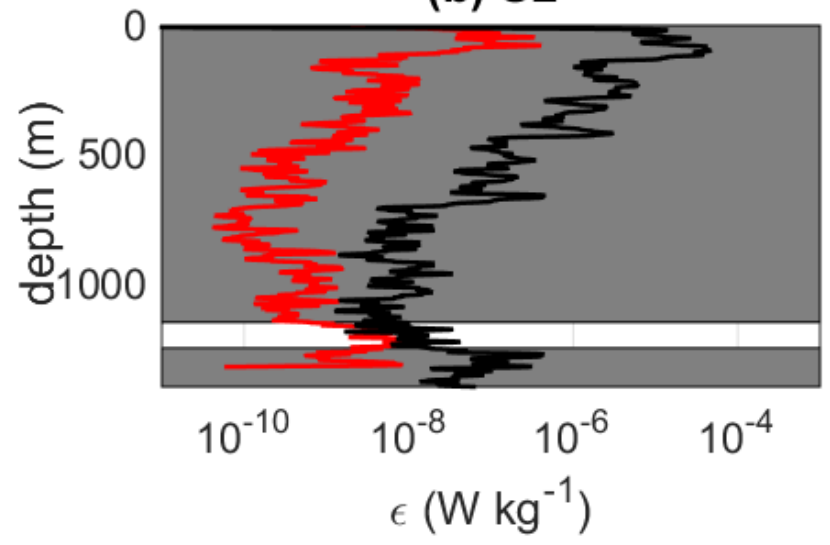

(d) $\mathrm{S5}$

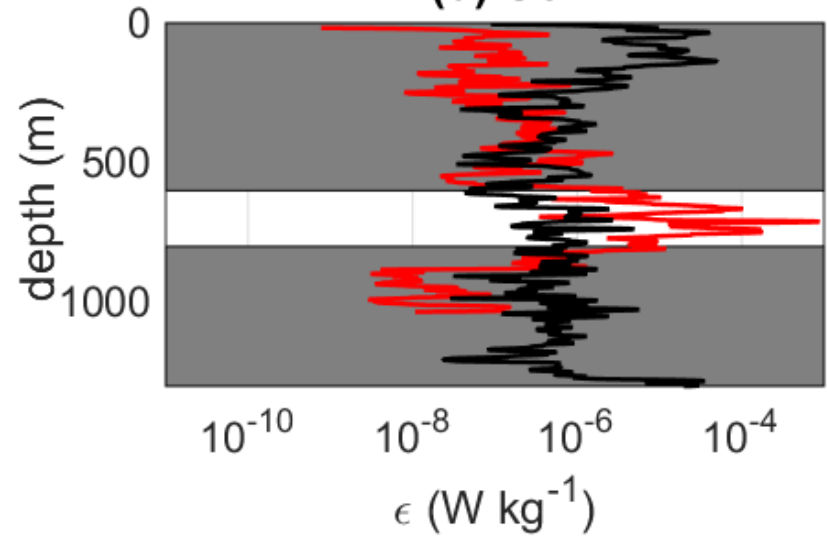

Figure 15: Mean profile of $\epsilon_{V M P}$ (red curve) and $\epsilon_{I R}$ (black curve) as a function of depth for station $S_{1}(a)$, station $S_{2}\left(\right.$ b), station $S_{3}\left(\right.$ c) and station $S_{5}(d)$. A 10-m moving average was applied to the mean profiles of $\epsilon_{V M P}$ and $\epsilon_{I R}$ for clarity. Gray shaded regions indicate depth intervals where $\epsilon_{\mathrm{IR}}$ is not relevant (mean Ozmidov scale smaller than $8 \mathrm{~m})$. 
(a) $\mathrm{S1}$

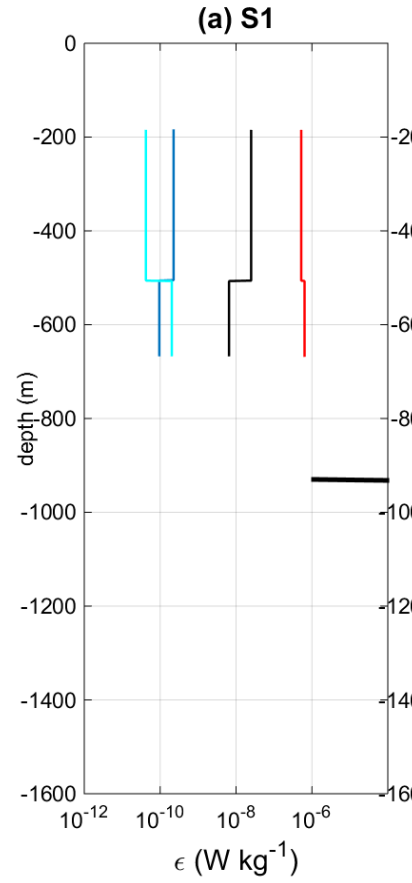

(b) $\mathrm{S2}$

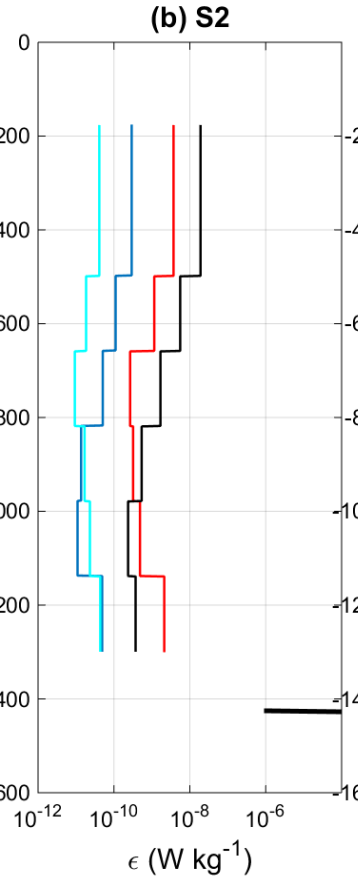

(c) $\mathrm{S3}$

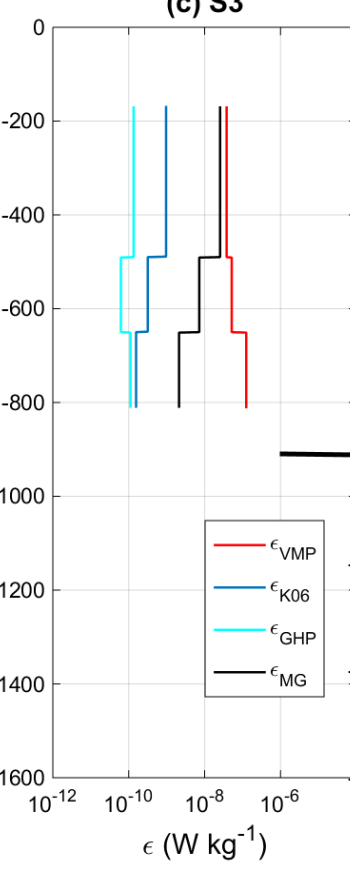

(d) $\mathrm{S4}$

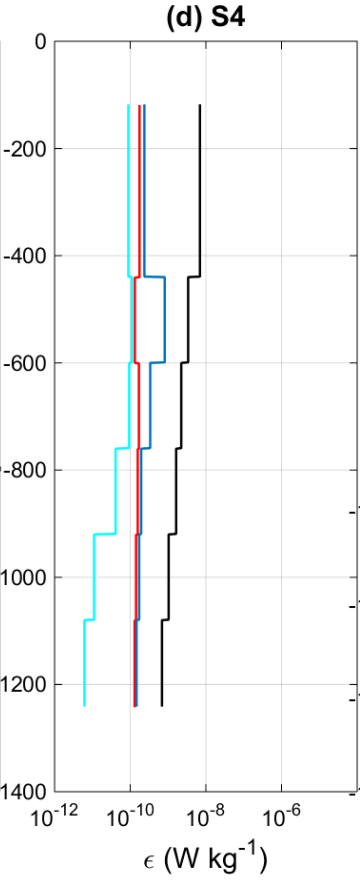

(e) $\mathbf{S 5}$

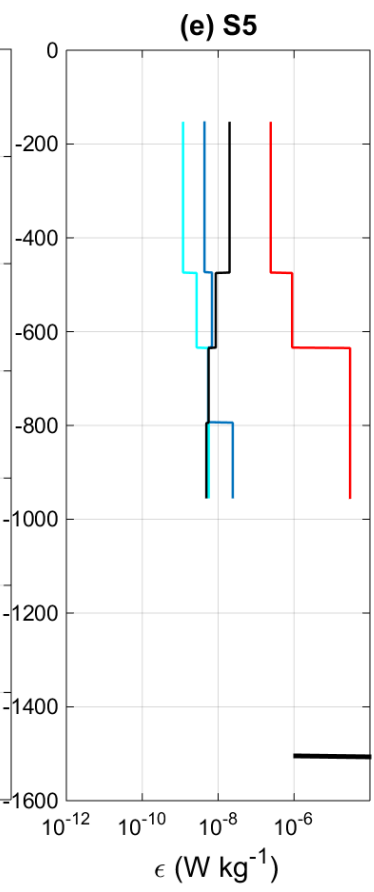

Figure 16: Mean profiles of $\epsilon$ derived from the Kunze et al. (2006) finescale parameterization at all stations, $\epsilon_{\mathrm{K} 06}$ is shown in blue, and $\left\langle\epsilon_{\mathrm{VMP}}>\right.$ averaged over the $320 \mathrm{~m}$ computation intervals with an overlap of $160 \mathrm{~m}$ in red. $\left\langle\epsilon_{\mathrm{GHP}}\right\rangle$ is shown as well for comparison. The bottom depth of the stations is indicated by a black horizontal line except for station $S_{4}$. 
Table 1: Position of the stations, depths and number of VMP profiles, maximum and mean of barotropic velocity modulus.

\begin{tabular}{|c|c|c|c|c|c|c|}
\hline Station & position & $\begin{array}{l}\text { averaged station } \\
\text { depth }(\mathrm{m})\end{array}$ & $\begin{array}{l}\text { number } \\
\text { of VMP }\end{array}$ & $\begin{array}{c}\text { maximum depth } \\
\text { of VMP }\end{array}$ & $\begin{array}{c}\max \left(v_{b t p}\right) \\
\left(m s^{-1}\right)\end{array}$ & $\begin{array}{c}\operatorname{mean}\left(v_{\mathrm{btp}}\right) \\
\left(\mathrm{m} \mathrm{s}^{-1}\right)\end{array}$ \\
\hline \multirow[t]{2}{*}{$S_{1}$} & $129.1742 \mathrm{E}$ & 962 & 5 & 720 & 0.71 & 0.32 \\
\hline & $0.0605 \mathrm{~N}$ & & & & & \\
\hline \multirow[t]{2}{*}{$\mathrm{S}_{2}$} & $128.883 \mathrm{OE}$ & 1407 & 10 & 1340 & 0.17 & 0.09 \\
\hline & $0.7520 S$ & & & & & \\
\hline \multirow[t]{2}{*}{$\mathrm{S}_{3}$} & $129.7630 \mathrm{E}$ & 914 & 14 & 900 & 0.28 & 0.17 \\
\hline & $1.1357 \mathrm{~S}$ & & & & & \\
\hline \multirow[t]{2}{*}{$\mathrm{S}_{4}$} & $126.9980 \mathrm{E}$ & 4750 & 1 & 1270 & - & - \\
\hline & $6.2855^{S}$ & & & & & \\
\hline \multirow[t]{2}{*}{$\mathrm{S}_{5}$} & $125.244 \mathrm{OE}$ & 1501 & 6 & 1010 & 0.86 & 0.25 \\
\hline & $8.2838 S$ & & & & & \\
\hline
\end{tabular}


Table 2: Mean, standard deviation and extrema of $\epsilon_{\mathrm{VMP}}\left(\mathrm{W} \mathrm{kg}^{-1}\right)$ and of $\mathrm{K}_{z}\left(\mathrm{~m}^{2} \mathrm{~s}^{-1}\right)$. The average and standard deviation, $\sigma$, were first computed over time and next averaged over depth. The average of $\mathrm{K} z_{\mathrm{O} \text { sborn }}$ is displayed for comparison.

\begin{tabular}{cccccc}
\hline \hline Station & $\epsilon_{\text {arith }}$ & $\sigma_{\text {arith }}$ & $\epsilon_{\min }$ & $\epsilon_{\text {max }}$ & \\
\hline$S_{1}$ & $4.9 \times 10^{-7}$ & $6.4 \times 10^{-7}$ & $4.3 \times 10^{-11}$ & $4.2 \times 10^{-5}$ & \\
$S_{2}$ & $9.1 \times 10^{-9}$ & $1.5 \times 10^{-8}$ & $1.0 \times 10^{-11}$ & $5.8 \times 10^{-6}$ & \\
$S_{3}$ & $2.8 \times 10^{-7}$ & $2.3 \times 10^{-7}$ & $1.0 \times 10^{-11}$ & $6.2 \times 10^{-5}$ & \\
$S_{4}$ & $9.4 \times 10^{-10}$ & $3.9 \times 10^{-9}$ & $2.1 \times 10^{-11}$ & $3.6 \times 10^{-8}$ & \\
$S_{5}$ & $9.8 \times 10^{-6}$ & $1.5 \times 10^{-5}$ & $1.1 \times 10^{-11}$ & $3.5 \times 10^{-3}$ & \\
\hline \hline$S_{\text {Station }}$ & $\left(\mathrm{K}_{z}\right)_{\mathrm{arith}}$ & $\sigma_{\mathrm{arith}}$ & $\left(\mathrm{K}_{z}\right)_{\mathrm{min}}$ & $\left(\mathrm{K}_{z}\right)_{\mathrm{max}}$ & $\left(\mathrm{K}_{z}\right)_{\mathrm{Osborn}}$ \\
\hline \hline $\mathrm{S}_{1}$ & $9.4 \times 10^{-4}$ & $7.0 \times 10^{-4}$ & $2.6 \times 10^{-5}$ & $2.2 \times 10^{-2}$ & $4.7 \times 10^{-2}$ \\
$\mathrm{~S}_{2}$ & $7.6 \times 10^{-5}$ & $7.1 \times 10^{-5}$ & $6.0 \times 10^{-6}$ & $4.4 \times 10^{-4}$ & $1.9 \times 10^{-4}$ \\
$\mathrm{~S}_{3}$ & $3.7 \times 10^{-4}$ & $4.9 \times 10^{-4}$ & $1.8 \times 10^{-5}$ & $3.1 \times 10^{-3}$ & $1.1 \times 10^{-2}$ \\
$\mathrm{~S}_{4}$ & $1.2 \times 10^{-5}$ & $5.0 \times 10^{-5}$ & $1.0 \times 10^{-7}$ & $4.2 \times 10^{-4}$ & $3.7 \times 10^{-5}$ \\
$\mathrm{~S}_{5}$ & $1.9 \times 10^{-3}$ & $2.7 \times 10^{-3}$ & $2.4 \times 10^{-5}$ & $2.3 \times 10^{-2}$ & $4.9 \times 10^{-1}$ \\
\hline
\end{tabular}


Table 3: Same as Table 2 but within the thermocline. The depth range for thermocline statistics is $[50-200] \mathrm{m}$ except at station $\mathrm{S}_{4}$ with a $[50-120] \mathrm{m}$ depth range.

\begin{tabular}{|c|c|c|c|c|c|}
\hline Station & $\epsilon_{\text {arith }}$ & $\sigma_{\text {arith }}$ & $\epsilon_{\min }$ & $\epsilon_{\max }$ & \\
\hline$S_{1}$ & $3.1 \times 10^{-7}$ & $4.9 \times 10^{-7}$ & $6.5 \times 10^{-11}$ & $9.1 \times 10^{-6}$ & \\
\hline $\mathrm{S}_{2}$ & $4.2 \times 10^{-8}$ & $5.9 \times 10^{-8}$ & $3.8 \times 10^{-11}$ & $3.9 \times 10^{-6}$ & \\
\hline $\mathrm{S}_{3}$ & $7.7 \times 10^{-8}$ & $2.1 \times 10^{-7}$ & $6.3 \times 10^{-11}$ & $1.0 \times 10^{-5}$ & \\
\hline $\mathrm{S}_{4}$ & $4.9 \times 10^{-9}$ & $3.6 \times 10^{-9}$ & $5.8 \times 10^{-10}$ & $1.2 \times 10^{-8}$ & \\
\hline $\mathrm{S}_{5}$ & $9.4 \times 10^{-8}$ & $1.5 \times 10^{-7}$ & $5.2 \times 10^{-11}$ & $4.5 \times 10^{-6}$ & \\
\hline Station & $\left(\mathrm{K}_{z}\right)_{\text {arith }}$ & $\sigma_{\text {arith }}$ & $\left(\mathrm{K}_{z}\right)_{\min }$ & $\left(\mathrm{K}_{z}\right)_{\max }$ & $\left(\mathrm{K}_{z}\right)_{\text {Osborn }}$ \\
\hline $\mathrm{S}_{1}$ & $1.7 \times 10^{-4}$ & $1.9 \times 10^{-4}$ & $1.0 \times 10^{-7}$ & $2.0 \times 10^{-3}$ & $1.2 \times 10^{-3}$ \\
\hline $\mathrm{S}_{2}$ & $5.2 \times 10^{-5}$ & $6.1 \times 10^{-5}$ & $1.0 \times 10^{-7}$ & $5.0 \times 10^{-4}$ & $1.3 \times 10^{-4}$ \\
\hline$S_{3}$ & $4.6 \times 10^{-5}$ & $6.4 \times 10^{-5}$ & $1.0 \times 10^{-7}$ & $7.0 \times 10^{-4}$ & $9.5 \times 10^{-5}$ \\
\hline $\mathrm{S}_{4}$ & $1.8 \times 10^{-5}$ & $4.3 \times 10^{-5}$ & $1.0 \times 10^{-7}$ & $2.0 \times 10^{-4}$ & $3 \times 10^{-5}$ \\
\hline $\mathrm{S}_{5}$ & $6.4 \times 10^{-5}$ & $6.9 \times 10^{-5}$ & $5.3 \times 10^{-7}$ & $4.0 \times 10^{-4}$ & $1.2 \times 10^{-4}$ \\
\hline
\end{tabular}


Table 4: Percentage of agreement within a factor of 10 (1st column), 5 (2nd column) and 2 (3rd column) of $\epsilon_{\mathrm{IR}}$ for data such that $\mathrm{L}_{\mathrm{O}}>8 \mathrm{~m}$.

\begin{tabular}{cccc}
\hline \hline Station & $\epsilon_{\mathrm{IR}} / \epsilon$ within $[1 / 10,10]$ & $\epsilon_{\mathrm{IR}} / \epsilon$ within $[1 / 5,5]$ & $\epsilon_{\mathrm{IR}} / \epsilon$ within $[1 / 2,2]$ \\
\hline $\mathrm{S}_{1}$ & $94 \%$ & $86 \%$ & $78 \%$ \\
$\mathrm{~S}_{2}$ & $73 \%$ & $62 \%$ & $44 \%$ \\
$\mathrm{~S}_{3}$ & $91 \%$ & $85 \%$ & $75 \%$ \\
$\mathrm{~S}_{5}$ & $88 \%$ & $85 \%$ & $77 \%$ \\
\hline
\end{tabular}




\section{REFERENCES}

Alford, M., M. C. Gregg, and M. Ilyas, 1999: Diapycnal mixing in the Banda Sea: Results of the first microstructure measurements in the Indonesian Throughflow. Geophys. Res. Lett., 26 (17), 2741-2744.

Alford, M. H. and M. C. Gregg, 2001: Near-inertial mixing: Modulation of shear, strain and microstructure at low latitude. Journal of Geophysical Research, 106 (C8), 1694716968.

Atmadipoera, A., A. Koch-Larrouy, G. Madec, J. Grelet, I. Jaya, I. Nurjaya, and M. Purba, 2017: Hydrological measurements within the indonesian throughflow region: from INDOMIX cruise 2010; (in preparation).

Atmadipoera, A., R. Molcard, G. Madec, S. Wijffels, J. Sprintall, A. Koch-Larrouy, I. Jaya, and A. Supangat, 2009: Characteristics and variability of the Indonesian Throughflow water at the outflow straits. Deep Sea Research Part I: Oceanographic Research Papers, 56 (11), 1942-1954.

Baines, P., 1982: On internal tide generation models. Deep Sea Research Part A. Oceanographic Research Papers, 29 (3), 307-338.

Beaird, N., I. Fer, P. Rhines, and C. Eriksen, 2012: Dissipation of turbulent kinetic energy inferred from seagliders. Journal of Physical Oceanography, 42, 2268-2282. 
Bluteau, C., N. Jones, and G. Ivey, 2013: Turbulent mixing efficiency at an energetic ocean site. Journal of Geophysical Research: Oceans, 118 (9), 4662-4672.

Bouffard, D. and L. Boegman, 2013: A diapycnal diffusivity model for stratified environmental flows. Dynamics of Atmospheres and Oceans, 61, 14-34.

Bouruet-Aubertot, P., J. Sommeria, and C. Staquet, 1995: Breaking of standing internal gravity waves through two-dimensional instabilities. Journal of Fluid Mechanics, 285, 265-301.

Buijsman, M. C., S. Legg, and J. Klymak, 2012: Double-ridge internal tide interference and its effect on dissipation in luzon strait. Journal of Physical Oceanography, 42 (8), $1337-1356$.

Canuto, C., A. Quarteroni, M. Hussaini, and T. Zang, 1988: Spectral method in fluid mechanics. Springer-Verlag, New York.

Cuypers, Y., P. Bouruet-Aubertot, C. Marec, and J.-L. Fuda, 2012: Characterization of turbulence from a fine-scale parameterization and microstructure measurements in the Mediterranean Sea during the BOUM experiment. Biogeosciences, 9 (8), 3131-3149.

De Lavergne, C., G. Madec, J. Le Sommer, A. G. Nurser, and A. C. Naveira Garabato, 2016a: The impact of a variable mixing efficiency on the abyssal overturning. Journal of Physical Oceanography, 46 (2), 663-681.

De Lavergne, C., G. Madec, J. Le Sommer, A. G. Nurser, and A. C. Naveira Garabato, 2016b: On the consumption of antarctic bottom water in the abyssal ocean. Journal of Physical Oceanography, 46 (2), 635-661. 
Egbert, G. and R. Ray, 200o: Significant dissipation of tidal energy in the deep ocean inferred from satellite altimeter data. Nature, $405(6788), 775-778$.

Egbert, G. D. and S. Y. Erofeeva, 2002: Efficient inverse modeling of barotropic ocean tides. Journal of Atmospheric and Oceanic Technology, 19 (2), 183-204.

Egbert, G. D. and R. D. Ray, 2003: Semi-diurnal and diurnal tidal dissipation from TOPEX/POSEIDON altimetry. Geophysical Research Letters, 30 (17), 1907.

Ferron, B., F. Kokoszka, H. Mercier, and P. Lherminier, 2014: Dissipation rate estimates from microstructure and finescale internal wave observations along the A25 Greenland-Portugal OVIDE line. Journal of Atmospheric and Oceanic Technology, 31, 25302543 .

Ffield, A. and A. L. Gordon, 1992: Vertical mixing in the Indonesian thermocline. Journal of Physical Oceanography, 22 (2), 184-195.

Ffield, A. and A. L. Gordon, 1996: Tidal mixing signatures in the Indonesian Seas. Journal of Physical Oceanography, 26 (9), 1924-1937.

Ffield, A. and R. Robertson, 2005: Indonesian Seas finestructure variability. Oceanography, $18(4), 108-111$.

Ffield, A. and R. Robertson, 2008: Temperature finestructure in the Indonesian Seas. Journal of Geophysical Research, 113 (C9), Cog oog.

Garrett, C. and W. Munk, 1975: Space-time scales of internal waves: A progress report. Journal of Geophysical Research, 80 (3), 291-297. 
Gayen, B. and S. Sarkar, 2011: Boundary mixing by density overturns in an internal tidal beam. Geophysical Research Letters, 38 (14).

Gerkema, T., F.-P. A. Lam, and L. R. Maas, 2004: Internal tides in the Bay of Biscay: conversion rates and seasonal effects. Deep Sea Research Part II: Topical Studies in Oceanography, 51 (25), 2995-3008.

Gordon, A., et al., 2010: The Indonesian Throughflow during 2004-2006 as observed by the INSTANT program. Dynamics of Atmospheres and Oceans, 50 (2), 115-128.

Gordon, A. L., 1986: Interocean exchange of thermocline water. Journal of Geophysical Research: Oceans (1978-2012), 91 (C4), 5037-5046.

Gordon, A. L., 2005: The Indonesian Seas. Oceanography, 18 (4), 14-27.

Gordon, A. L. and R. A. Fine, 1996: Pathways of water between the Pacific and Indian Oceans in the Indonesian Seas. Nature, 379 (6561), 146-149.

Gregg, M., 1989: Scaling turbulent dissipation in the thermocline. Journal of Geophysical Research, $94\left(C_{7}\right), 9686-9698$.

Gregg, M., M. Alford, H. Kontoyiannis, V. Zervakis, and D. Winkel, 2012: Mixing over the steep side of the cycladic plateau in the aegean sea. Journal of Marine Systems, 89 (1), $30-47$

Gregg, M. C., T. B. Sanford, and D. P. Winkel, 2003: Reduced mixing from the breaking of internal waves in equatorial waters. Nature, 422 (6931), 513-515. 
Henyey, F. S., J. Wright, and S. M. Flatté, 1986: Energy and action flow through the internal wave field: An eikonal approach. Journal of Geophysical Research: Oceans (19782012), 91 (C7), 8487-8495.

Huussen, T., A. Naveira-Garabato, H. Bryden, and E. McDonagh, 2012: Is the deep indian ocean moc sustained by breaking internal waves? Journal of Geophysical Research: Oceans, 117 (C8).

Klymak, J. M., S. Legg, and R. Pinkel, 2010: A simple parameterization of turbulent mixing near supercritical topography. Journal of Physical Oceanography, 40 (9), 20592074 .

Koch-Larrouy, A., A. Atmadipoera, P. Van Beek, G. Madec, J. Aucan, F. Lyard, J. Grelet, and M. Souhaut, 2015: Estimates of tidal mixing in the indonesian archipelago from multidisciplinary indomix in-situ data. Deep Sea Research Part I: Oceanographic Research Papers, 106, 136-153.

Koch-Larrouy, A., G. Madec, D. Iudicone, A. Atmadipoera, and R. Molcard, 2008: Physical processes contributing to the water mass transformation of the Indonesian Throughflow. Ocean Dynamics, 58 (3-4), 275-288.

Kunze, E., E. Firing, J. M. Hummon, T. K. Chereskin, and A. M. Thurnherr, 2006: Global abyssal mixing inferred from lowered ADCP shear and CTD strain profiles. Journal of Physical Oceanography, 36 (8), 1553-1576. 
Legg, S. and K. M. Huijts, 2006: Preliminary simulations of internal waves and mixing generated by finite amplitude tidal flow over isolated topography. Deep Sea Research Part II: Topical Studies in Oceanography, 53 (1), 140-156.

Lelong, M. and T. Dunkerton, 1998a: Inertia-gravity wave breaking in three dimensions. part i: convectively stable waves. Journal of Atmospheric Sciences, 55 (15), 2473-2488.

Lelong, M. and T. Dunkerton, 1998b: Inertia-gravity wave breaking in three dimensions. part ii: convectively unstable waves. Journal of Atmospheric Sciences, 55 (15), 2489-2501.

Lelong, M.-P. and E. Kunze, 2013: Can barotropic tide-eddy interactions excite internal waves? Journal of Fluid Mechanics, 721, 1-27.

Llewellyn Smith, S. G. and W. Young, 2003: Tidal conversion at a very steep ridge. Journal of Fluid Mechanics, 495, 175-191.

Lyard, F. and C. Le Provost, 2002: Energy budget of the tidal hydrodynamic model fes99. Appears in C. Le Provosts' talk: "Ocean tides after a decade of high precision satellite altimetry", SWT Jason, $\mathbf{1}$.

MacKinnon, J. and M. Gregg, 2003: Mixing on the late-summer New England Shelfsolibores, shear, and stratification. Journal of Physical Oceanography, 33 (7), 1476-1492.

MacKinnon, J. and M. Gregg, 2005: Spring mixing: Turbulence and internal waves during restratification on the New England Shelf. Journal of Physical Oceanography, 33 (12), $2425-2443$. 
Manders, A., L. Maas, and T. Gerkema, 2004: Observations of internal tides in the mozambique channel. Journal of Geophysical Research: Oceans, 109 (C12).

Mathur, M., G. S. Carter, and T. Peacock, 2014: Topographic scattering of the low-mode internal tide in the deep ocean. Journal of Geophysical Research: Oceans, 119 (4), 21652182.

McComas, C. H. and P. Müller, 1981: The dynamic balance of internal waves. Journal of Physical Oceanography, 11 (7), 970-986.

Moum, J. N., 1996: Energy-containing scales of turbulence in the ocean thermocline. Journal of Geopysical Research, 101 (C6), 14,095-14,109.

Nagai, T. and T. Hibiya, 2015: Internal tides and associated vertical mixing in the indonesian archipelago. Journal of Geophysical Research: Oceans, 1977-2010.

Nagai, T., T. Hibiya, and P. Bouruet-Aubertot, 2017: Nonhydrostatic simulations of tideinduced mixing in the halmahera sea: A possible role in the transformation of the indonesian throughflow waters. Journal of Geophysical Research: Oceans.

Nasmyth, P. W., 1970: Oceanic turbulence.

Naveira Garabato, A. C., K. I. Oliver, A. J. Watson, and M.-J. Messias, 2004: Turbulent diapycnal mixing in the nordic seas. Journal of Geophysical Research: Oceans, 109 (C12).

Osborn, T., 1980: Estimates of the local rate of vertical diffusion from dissipation measurements. Journal of Physical Oceanography, 1o (1), 83-89. 
Pasquet, S., P. Bouruet-Aubertot, G. Reverdin, A. Turnherr, and L. St Laurent, 2016: Validation of fine-scale parameterization of energy dissipation in a region of strong internal tides and sheared flow, the lucky-strike segment of the mid-atlantic ridge. Deep-Sea Research, 112, 79-93.

Peters, H., M. C. Gregg, and T. B. Sanford, 1995: Detail and scaling of turbulent overturns in the pacific equatorial undercurrent. Journal of Geophysical Research: Oceans, $\mathbf{1 0 0}$ (C9), $18349-18368$.

Polzin, K., E. Kunze, J. Hummon, and E. Firing, 2002: The finescale response of lowered ADCP velocity profiles. Journal of Atmospheric and Oceanic Technology, 19 (2), 205-224.

Polzin, K. L., A. C. Naveira Garabato, T. N. Huussen, B. M. Sloyan, and S. Waterman, 2014: Finescale parameterizations of turbulent dissipation. Journal of Geophysical Research: Oceans, 119 (2), 1383-1419.

Polzin, K. L., J. M. Toole, and R. W. Schmitt, 1995: Finescale parameterizations of turbulent dissipation. Journal of Physical Oceanography, 25 (3), 306-328.

Rainville, L., T. S. Johnston, G. S. Carter, M. A. Merrifield, R. Pinkel, P. F. Worcester, and B. D. Dushaw, 2010: Interference pattern and propagation of the $\mathrm{m} 2$ internal tide south of the hawaiian ridge. Journal of Physical Oceanography, 40 (2), 311-325.

Robertson, R., 2010: Tidal currents and mixing at the INSTANT mooring locations. Dynamics of Atmospheres and Oceans, 50, 331-373.

Robertson, R. and A. Ffield, 2008: Baroclinic tides in the Indonesian Seas: Tidal fields and comparisons to observations. Journal of Geophysical Research, $\mathbf{1 1 3}\left(\mathbf{C}_{7}\right)$. 
Schiller, A., S. Wijffels, J. Sprintall, R. Molcard, and P. R. Oke, 2010: Pathways of intraseasonal variability in the indonesian throughflow region. Dynamics of atmospheres and oceans, $50(2), 174-200$.

Shih, L. H., J. R. Koseff, G. N. Ivey, and J. H. Ferziger, 2005: Parameterization of turbulent fluxes and scales using homogeneous sheared stably stratified turbulence simulations. Journal of Fluid Mechanics, 525, 193-214.

Simmons, H. L., R. W. Hallberg, and B. K. Arbic, 2004: Internal wave generation in a global baroclinic tide model. Deep Sea Research Part II: Topical Studies in Oceanography, $51(25), 3043-3068$.

Sprintall, J., et al., 2004: Instant: A new international array to measure the Indonesian Throughflow. Eos, Transactions American Geophysical Union, 85 (39), 369-376.

St Laurent, L. C. and A. M. Thurnherr, 2007: Intense mixing of lower thermocline water on the crest of the mid-atlantic ridge. Nature, 448 (7154), 680-683.

Taylor, G. I., 1935: Statistical theory of turbulence. Proceedings of the Royal Society of London A: Mathematical, Physical and Engineering Sciences, The Royal Society, Vol. 151, 421-444.

Tennekes, H. and J. L. Lumley, 1972: A first course in Turbulence. MIT press.

van Haren, H., A. Cimatoribus, and L. Gostiaux, 2015: Where large deep-ocean waves break. Geophysical Research Letters, 42 (7), 2351-2357. 
Visbeck, M., 2002: Deep velocity profiling using lowered acoustic doppler current profilers: Bottom track and inverse solutions*. Journal of Atmospheric and Oceanic Technology, 19 (5), 794-807.

Walter, M., C. Mertens, and M. Rhein, 2005: Mixing estimates from a large-scale hydrographic survey in the north atlantic. Geophysical research letters, 32 (13).

Waterman, S., A. C. Naveira Garabato, and K. L. Polzin, 2013: Internal waves and turbulence in the antarctic circumpolar current. Journal of Physical Oceanography, 43 (2), $259-282$.

Wijesekera, H., L. Padman, T. Dillon, M. Levine, C. Paulson, and R. Pinkel, 1993: The application of internal-wave dissipation models to a region of strong mixing. Journal of Physical Oceanography, 23, 269-286.

Xie, X., Y. Cuypers, P. Bouruet-Aubertot, B. Ferron, A. Pichon, A. Lourenço, and N. Cortes, 2013: Large-amplitude internal tides, solitary waves, and turbulence in the central Bay of Biscay. Geophysical Research Letters, 40, 2748-2754. 